\title{
Chemistry of alkaline earth metals: It is not all ionic and definitely not boring!
}

\author{
Katharina M. Fromm \\ University of Fribourg, Department of Chemistry, Chemin du Musée 9, CH-1700 Fribourg, Switzerland
}

\begin{abstract}
Some scientists might consider group 2 chemistry as "boring, closed shell and all ionic, aqueous chemistry, where everything is known! It is not worth investigating". How wrong they are! Far from forming only purely ionic compounds, this review will shed light on some spectacular molecules, showing that alkaline earth metal ions can behave similar to transition metal ions. After general remarks about each element, from beryllium to barium, mainly recent examples of group 2 coordination compounds will be presented, their bonding situation will be discussed and examples of applications, e.g. in catalysis, will be given.
\end{abstract}

\section{Contents}

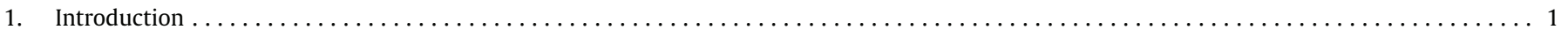

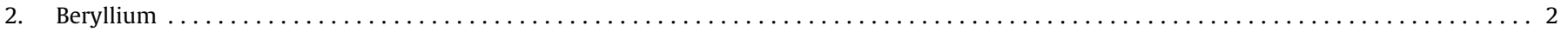

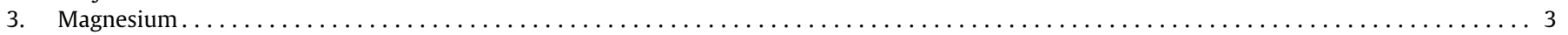

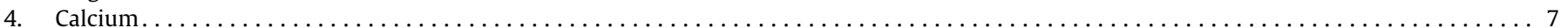

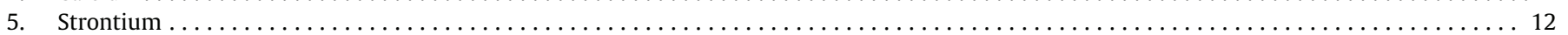

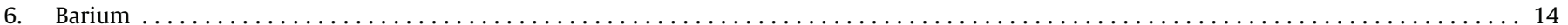

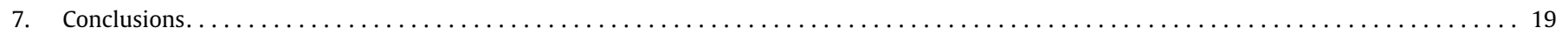

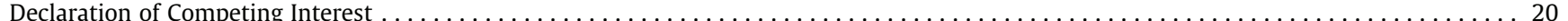

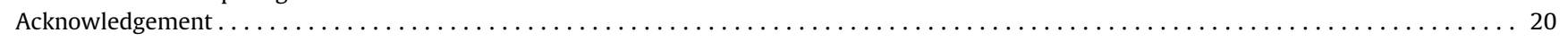

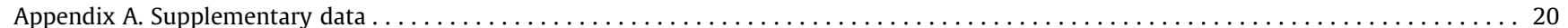

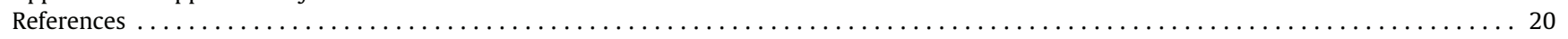

\section{Introduction}

The name "alkaline earth" comes from alchemist times and relates to their basic oxides, while "alkali" derives from the Arab term for "ashes of the saltwort", saltwort being flowering plants growing in a salty environment. The alkaline earth metal elements $\mathrm{Be}, \mathrm{Mg}, \mathrm{Ca}, \mathrm{Sr}, \mathrm{Ba}$, and Ra are all silvery shining metals with an $n s^{2}$ electronic configuration. Some of the alkaline earth compounds are known since prehistoric times, like gypsum, limestone or chalk, while others have been discovered between the 17th and the 19 th century.

Their electron affinity as well as the ionization energies are low, resulting in the formation of typically divalent cations $\mathrm{M}^{2+}$ upon

E-mail address: Katharina.fromm@unifr.ch oxidation. As usual in the main groups of the periodic table, the first element, Be here, behaves "not like the others". It has the highest electronegativity of all the alkaline earth metal elements with 1.57 (Pauling scale), followed by Mg with 1.31, while the heavier elements have an electronegativity of around 1.0. Beryllium also has the highest melting and boiling point in the group 2, which can be explained by strong interactions between the atoms due to a better orbital overlap. The chemistry is hence mainly covalent for Be, while it becomes generally more ionic as one moves down in the group.

Due to their high, but less violent reactivity when exposed to air and humidity compared to the group 1 elements, the alkaline earth metals are usually not found in their elemental state in nature, but are rather associated to minerals. The elements can be extracted from the molten compounds using electrolysis (Mg-Ra), or by 
reduction with a less noble alkali metal $(\mathrm{Be})$. Among the typical minerals of the alkaline earth metals, the transparent, colorless beryl is an aluminium cyclosilicate of beryllium. It adopts different colors when doped with iron or chromium ions, leading to the light blue aquamarine $\left(\mathrm{Fe}^{2+}\right.$-doping), the green emerald $\left(\mathrm{Cr}^{3+}\right)$ or the golden helidor $\left(\mathrm{Fe}^{3+}\right)$. Manganese doping leads to the pink morganite $\left(\mathrm{Mn}^{2+}\right)$ or the red beryl $\left(\mathrm{Mn}^{3+}\right)$. Magnesium, together with calcium among the ten most abundant elements on Earth's crust, is typically found as carbonate, either alone (magnesite) or with the latter (dolomite), or in silicates (e.g. talc) or other (soluble) salts. Calcium carbonate is the most frequent mineral for this element, but others, like limestone, gypsum, fluorite or apatite are also widely found. Celestine $\left(\mathrm{SrSO}_{4}\right)$ and strontianite $\left(\mathrm{SrCO}_{3}\right)$ are the most common sources for the production of strontium, and for barium, the analogue minerals are called barite, respectively whiterite. The radioactive element radium, discovered by Marie and Pierre Curie, does not present its own mineral, but is associated with uranium and thorium ores.

The coordination chemistry of the alkaline earth metal ions has been reviewed previously [1], covering earlier references, so that this review focuses mostly on selected examples of the more recent literature. Based on the large electronegativity difference between the alkaline earth metals and their most frequent binding partners, the metal-ligand interactions are mainly considered as -predominantly ionic and, due to usually negligible orbital interactions, also as non-directional based on ionic potentials. Hence, the interactions of ligands with the $\mathrm{M}^{2+}$ metal ion are therefore mostly governed by electrostatic and steric factors. There are however observations, such as unusual geometries, or good solubility in organic solvents, that hint to bonds with covalent character in certain alkaline earth metal compounds that will be particularly discussed for each element in the following chapters.

\section{. Beryllium}

Beryllium is the least reactive metal among the alkaline earth metals and reacts with oxygen only upon heating. It is therefore used either pure or as ingredient in alloys for many different applications. For example, since it has a low absorption for X-rays, it is sed in high purity as radiation windows for X-ray tubes, detectors and in synchrotrons. In alloys with other metals, it improves the mechanical strength and dimensional stability. Thus, it can be alloyed with copper or nickel, leading to metallic materials combining elasticity, high electronic and heat conductivity, and resistance to corrosion and fatigue. It can be used for watch springs, surgical instruments or non-sparking tools, e.g. to work with inflammable gases. Being non-magnetic, beryllium tools are chosen when working with magnetic compounds or strong magnetic fields.

While well known in alloys, molecular zero-valent beryllium compounds were first predicted by theory [2] and their existence was confirmed in 2016 with two examples, a homo- and a heteroleptic complex based on $\mathrm{N}$-heterocyclic carbene ligands (Fig. 1) [3]. Beryllium has then a linear coordination based on $\mathrm{Be}-\mathrm{C}$ bonds of ca. $1.66 \AA$, which is significantly shorter than in similar $\mathrm{Be}^{2+}$ compounds (ca. $1.78 \AA$ ) and hence shows the partial double-bond character based on the effect of the $\pi$-back-bonding from beryllium to the carbene in addition to the $\sigma$-donation by the carbene ligands to the metal atom. The electronic configuration of the beryllium atom is suggested therefore to be $1 s^{2} 2 s^{0} 2 p^{2}$ with the $2 \mathrm{e}-\pi$-bond stretching over the three-atom core of $\mathrm{C}-\mathrm{Be}-\mathrm{C}[3]$.

Covalent, electron-deficient chemical bonds (three-center-two electrons; 3c-2e) are also found in solid beryllium hydride $\left(\mathrm{BeH}_{2}\right)_{\mathrm{n}}$, where a network of corner-sharing $\mathrm{BeH}_{4}$-tetrahedra is formed [4]. Here, beryllium shows a diagonal relationship with aluminium and its hydride $\left(\mathrm{AlH}_{3}\right)_{\mathrm{n}}$, which is also a polymer, but is based on hexacoordinated aluminium ions featuring six 3c-2e bonds [5]. In the gas phase, $\mathrm{BeH}_{2}$ is linear with an $s p$-hybridisation [6]. The fluoride of beryllium behaves similarly to the hydride in the solid and in the gas phase, while beryllium chloride (and bromide and iodide) forms one-dimensional chains via edge-shared tetrahedra in the solid phase, and linear monomers as well as chloride-bridged dimers for $\mathrm{BeCl}_{2}$ with 3-coordinate beryllium in the gas phase [7]. In contrast to the insoluble hydride, the beryllium fluoride possesses ionic bonds, making it well soluble in water.

In water, the divalent beryllium ion behaves as a cation acid and is thus able to hydrolyze water molecules. From tetrahedrally coordinated $\left[\mathrm{Be}\left(\mathrm{OH}_{2}\right)_{4}\right]^{2+}$, obtained by dissolving beryllium salts in water, hydrolysis occurs to yield $\left[\mathrm{Be}\left(\mathrm{OH}_{2}\right)_{3}(\mathrm{OH})\right]^{+}$species that easily condensate into the trimeric $\left[\mathrm{Be}_{3}(\mathrm{OH})_{3}\left(\mathrm{OH}_{2}\right)_{6}\right]^{3+}[8]$. $\left[\mathrm{Be}(\mathrm{OH})_{2}\right]$ precipitates above $\mathrm{pH} 5$ and redissolves in basic medium to give the tetrahedral anion $\left[\mathrm{Be}(\mathrm{OH})_{4}\right]^{2-}[9]$.

The coordination chemistry of beryllium ions is thus typically dominated by tetrahedral coordination, as recently reviewed by others [10] that can be derived from both, VSEPR (Valence Shell Electron Pair Repulsion) and hybridization models. O- and Ndonors can lead to monomeric complexes, ring-type structures, aggregates or coordination polymers. For example, while basic beryllium acetate forms a $\left[\mathrm{Be}_{4}(\mathrm{O})(\mathrm{OAc})_{6}\right]$ aggregate (Fig. 2, left) [10], the reaction of $\mathrm{BeCl}_{2}$ with benzoic acid in benzene leads to elimination of $\mathrm{HCl}$ and formation of a $\mathrm{Be}_{12}$-ring molecule $\left[\mathrm{Be}(\mathrm{PhCOO})_{2}\right]_{12}$ (Fig. 2), which resembles wheel-type structures obtained with transition metal ions [11]. The tetrahedron around
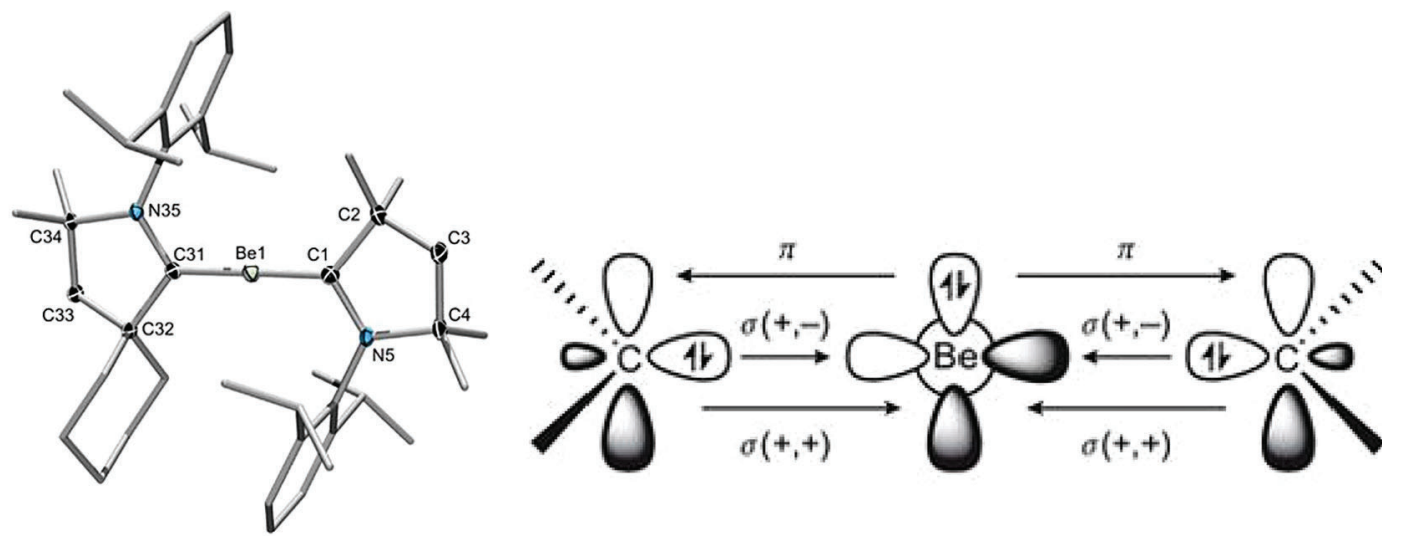

Fig. 1. Heteroleptic zero-valent beryllium compound stabilized with $\mathrm{N}$-heterocyclic carbene ligands (left) and schematic representations of the involved $\sigma$-donation and $\pi$ backdonation (right, adapted with permission from [3]). 


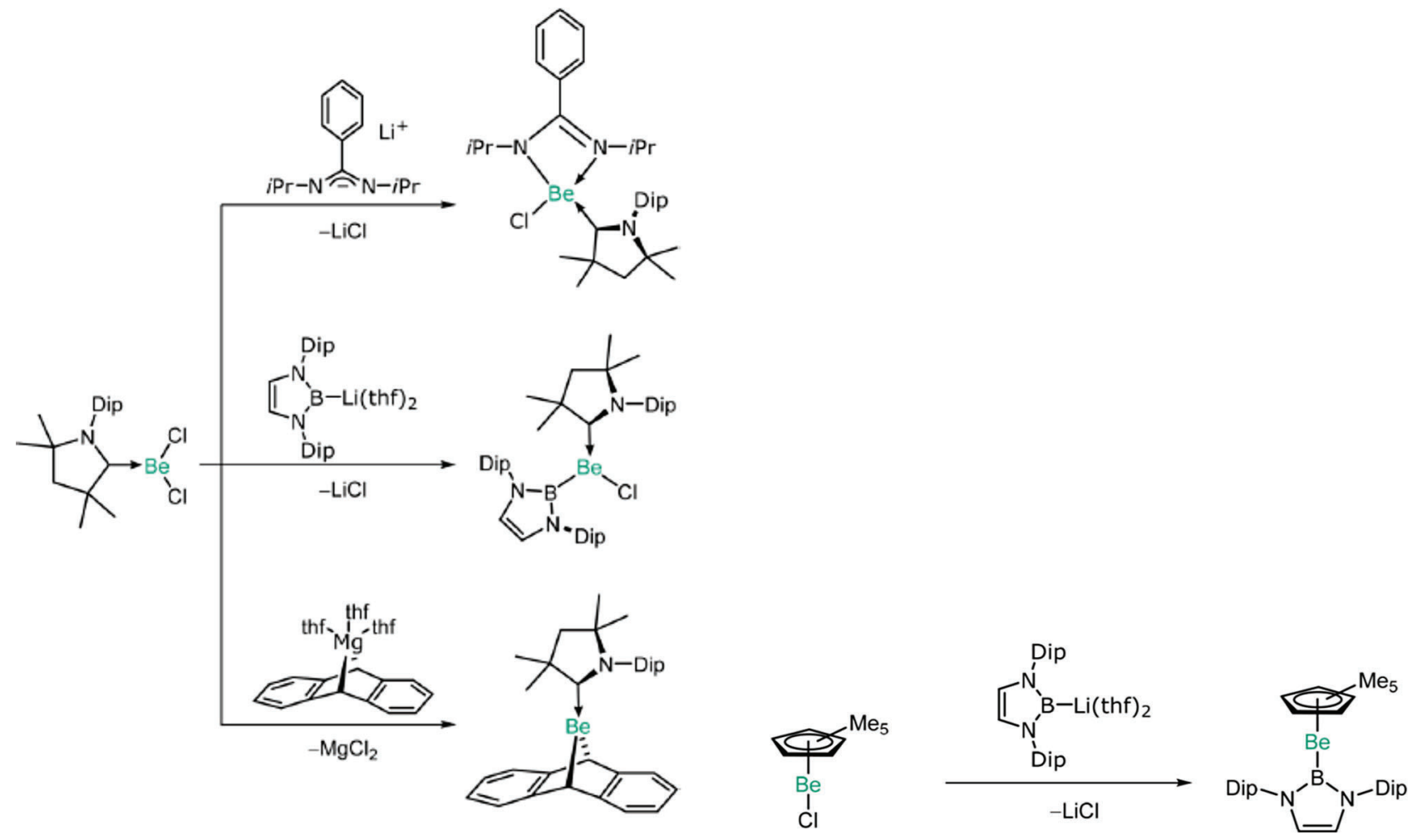

Scheme 1. Examples of new organo-beryllium compounds (reproduced with permission from [14]).<smiles></smiles><smiles></smiles>

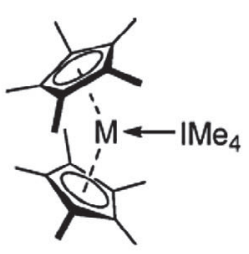

$\mathrm{M}=\mathrm{Ca}, \mathrm{Sr}, \mathrm{Ba}$

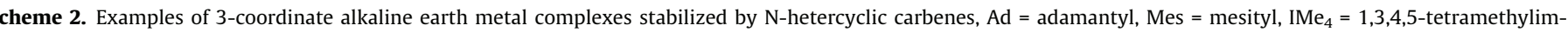
tazolin-2-ylidene (adapted with permission from [15]).

one corresponding to sigma-bonding, responsible for the superconductivity, the other corresponding to $\pi$-bonding interactions.

Magnesium has recently also been investigated as alternative electrode material for lithium in batteries [17]. In this context, triflic acid [18] and trifluoromethanesulfonate [19] magnesium complexes with tetraglyme were investigated for improving the electrolyte properties.

Magnesium is, like beryllium, also able to form organometallic compounds, featuring (polar) covalent bonds between the metal ion and carbon. The famous Grignard compounds are obtained through an "Umpolung" of the carbon atom, inserting the electropositive magnesium into a carbon-halide bond. In a recent study, dimethylmagnesium was shown to possess the same structure than dimethylberyllium, namely a one-dimensional chain structure, in which the tetrahedrally coordinated alkaline earth metal ions are bridged by the methyl groups [20]. Some recent examples on how to obtain Grignard compounds use one or two $\mathrm{N}$-heterocyclic carbene ligands on magnesium halides [21]. In contrast to beryllium, magnesium typically tends to have higher coordination numbers, as exemplified in the carbene chemistry of both metal ions [22]. Indeed, with the same N-heterocarbene ligand, the magnesium compound rather forms a dimer with bridging halide anions and coordination number 4 , while beryllium forms a monomer with coordination number 3 (Fig. 4, top).

While most of its coordination chemistry is dominated by $\mathrm{Mg}^{2+}$, these $\mathrm{N}$-heterocyclic carbenes can be reduced at least once using $\mathrm{KC}_{8}$, leading to a complex in which the radical is then stabilized by a chelating $\mathrm{N}$-donor ligand such as bipyridine (Fig. 4 , bottom) [22].

$\mathrm{Mg}^{+}$-compounds with a $\mathrm{Mg}-\mathrm{Mg}$ bond (Scheme 3) have been obtained by reduction with potassium, yielding $[(\mathrm{L}) \mathrm{MgMg}(\mathrm{L})]$, where $\mathrm{L}$ is $\left\{(\mathrm{Ar}) \mathrm{NC}\left(\mathrm{NPr}_{2}^{\mathrm{i}}\right) \mathrm{N}(\mathrm{Ar})\right\}^{-}$or $\left\{[(\mathrm{Ar}) \mathrm{NC}(\mathrm{Me})]_{2} \mathrm{CH}\right\}^{-}(\mathrm{Ar}=2,6$-dii sopropylphenyl, $\mathrm{Me}=$ methyl, $\operatorname{Pr}^{\mathrm{i}}=$ isopropyl) [23]. While the HOMO orbital comprises the $\sigma$-bond, the two lowest unoccupied orbitals, calculated for a model compound $\left\{\mathrm{Mg}\left[\left(\mathrm{Ar}^{\prime} \mathrm{N}\right)_{2} \mathrm{C}\left(\mathrm{NMe}_{2}\right)\right]_{2}\right.$ with $\mathrm{Ar}{ }^{\prime}=\mathrm{C}_{6} \mathrm{H}_{3} \mathrm{Me}_{2}-2,6$ are almost degenerate with only $0.11 \mathrm{eV}$ $(=2.6 \mathrm{kcal} / \mathrm{mol})$ energy difference and stem mostly from metalmetal $\pi$-bonding orbitals derived from metal $p_{\mathrm{x}}$ - and $p_{\mathrm{y}}$-orbital overlaps. Such compounds can be used as $2 \mathrm{e}^{-}$-reductants with $\mathrm{CO}$ to yield dimeric deltate complexes [24]. They can also lead to non-cyclic 1,2dimagnesioethane or -ethene compounds that can be useful as multipurpose reagents for organometallic synthesis [25].

$\mathrm{Mg}^{+}$-halides have been studied in comparison with magnesium metal as reducing agents, for instance in the reaction with $\mathrm{P}-\mathrm{Cl}$ 

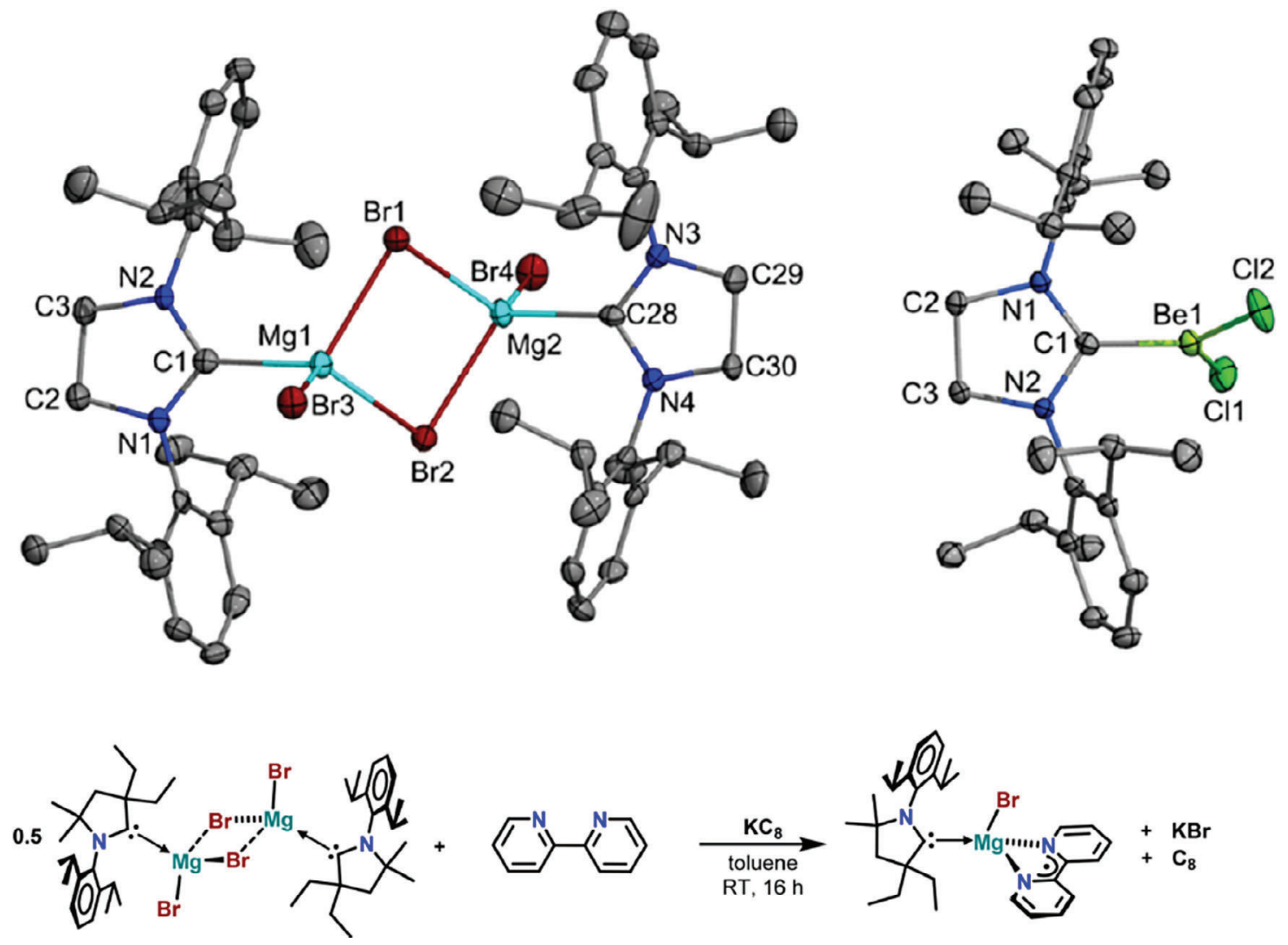

Fig. 4. Top: Comparison of coordination number for $\mathrm{Mg}^{2+}$ (left) and $\mathrm{Be}^{2+}$ (right) with the same N-heterocyclic carbene ligand (adapted from [22]); Bottom: Reduction of such complexes in presence of chelating $\mathrm{N}$-donor ligands to form radical species (adapted with permission from [22]).

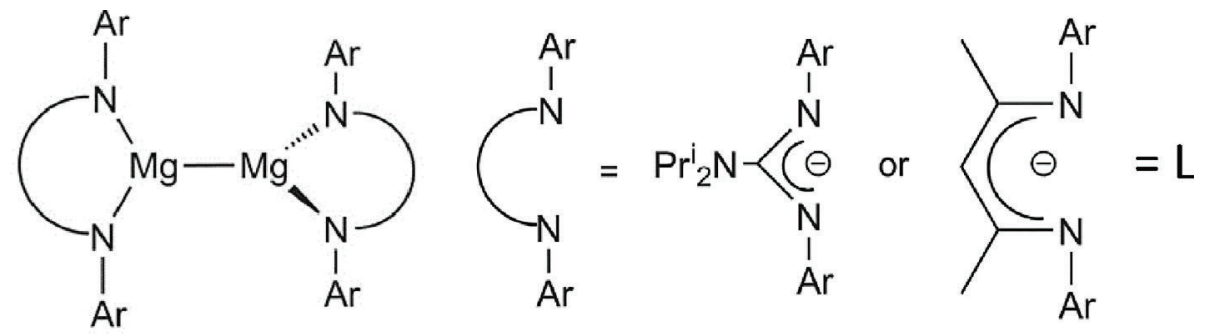

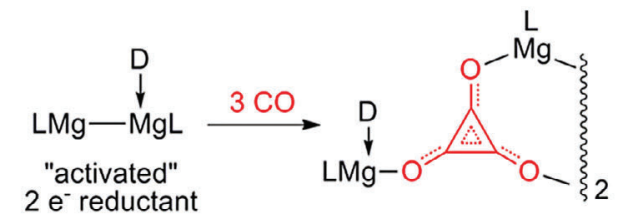

Scheme 3. $\mathrm{Mg}^{+}$-compounds obtained via reduction of $\mathrm{Mg}^{2+}$-precursors with potassium, $\mathrm{Ar}=2,6$-diisopropylphenyl, $\mathrm{D}=\mathrm{N}$-heterocyclic carbene, or 4-dimethylaminopyridine (adapted with permission from [23;24]).

bonds [26]. The same reference mentions also relatively stable (with respect to disproportionation into $\mathrm{Mg}^{0}$ and $\mathrm{Mg}^{2+}$ species) biradical species such as $\left[\mathrm{MgBr}\left(\mathrm{N}^{\mathrm{n}} \mathrm{Bu}_{3}\right)\right]_{2}$ and metalloid clusters like the anionic $\left[\mathrm{Mg}_{16} \mathrm{Cp}_{8}{ }_{8} \mathrm{Br}_{4} \mathrm{~K}\right]^{-}$, whose proposed structure was calculated to possess multiple $\mathrm{Mg}-\mathrm{Mg}$ bonds.

Recent results for $\mathrm{Mg}^{2+}$ compounds include studies on hydrogen storage, which lead to new N-donor-ligand stabilized oligomers of magnesium hydride, releasing up to five equivalents of $\mathrm{H}_{2}$ (Fig. 5a) [27]. Similarly, magnesium carbonate clusters were calculated in the context of possible $\mathrm{CO}_{2}$-storage intermediates [28]. Along those lines, the parent oxide clusters were predicted not only for magne- sium, but also calcium and strontium, and compared to the barium oxide aggregates [29].

While compounds with hetero metal-metal bonds, like in $\mathrm{Cu}-$ $\mathrm{Mg}$ or the recent $\mathrm{Mg}-\mathrm{Pd}$ compounds described by Crimmin et al [30,31] or the above-mentioned $\mathrm{Mg}^{+}$-compounds [22-24] as well as the hydrides with sterically demanding ligands [27], feature coordination number 3 or 4 (tetrahedral) for the alkaline earth metal, the $\mathrm{Mg}^{2+}$ ion, like for beryllium, can also be coordinated in a square planar fashion in e.g. porphyrins [32]. Low coordination numbers can in general be achieved with bulky ligands, as exemplified in a study on dithiolenes [33]. Coordination number 5 has 


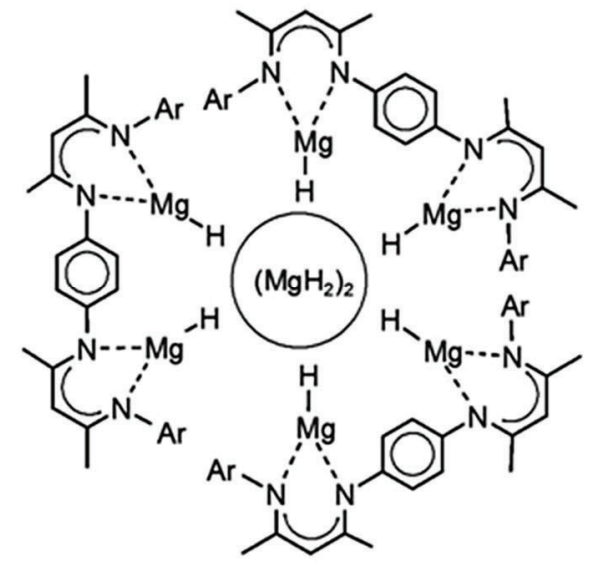

(a)

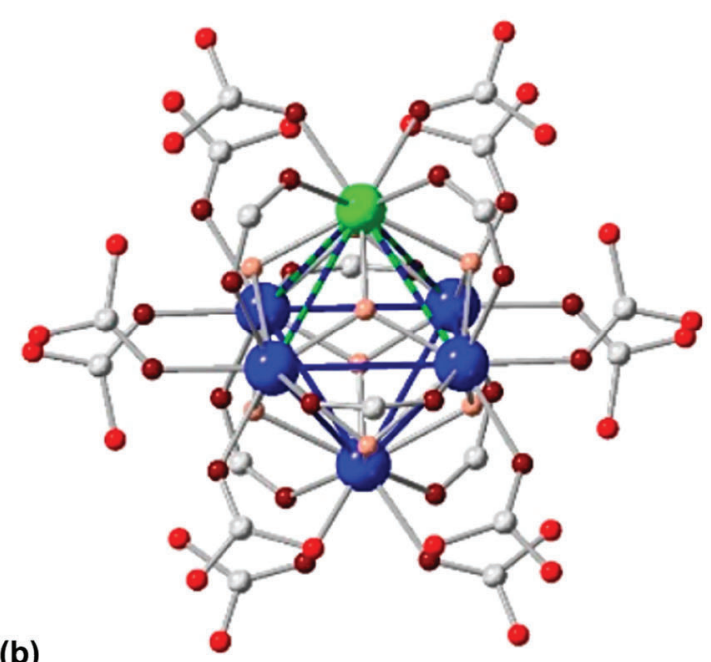

(b)

Fig. 5. a) Magnesium hydride cluster stabilized by sterically demanding N-donor ligands, able to release 5 equivalents of $\mathrm{H}_{2}$ upon heating (adapted from Ref. [27]); b) $\mathrm{MgZr}_{5} \mathrm{O}_{2}(\mathrm{OH})_{6}$ clusters present in MOFs with improved catalytic properties towards nerve agent decomposition (Mg: green, $\mathrm{Zr}$ : blue, O: red taints, C: grey; blue and greenblue lines indicate geometry, no chemical bonds; adapted with permission from [43]).

U been realized for instance in some 1,4-dioxane complexes of di(hydrocarbyl)magnesium compounds, depending on the size of the organic group [34], as well as with the help of capping $\mathrm{N}$-donor ligands, i.e. with amide ligands [35]. Six-coordinate magnesium compounds are for instance used for catalysis, as exemplified by the complex of $\mathrm{Mg}^{2+}$ with ketoimine ligands such as $\mathrm{N}$-quinolyl-2 -imino-5,5-dimethyl-hex-4-one that has been useful in the ring -opening polymerization and copolymerization of L-lactide and $\epsilon$ -

Caprolactone [36]. Coordination number 6, based on (distorted) octahedra, is also often observed in coordination polymers with polydentate carboxylic acid ligands [37]. Some magnesium-based stable metal organic frameworks (MOFs) have been obtained, exhibiting for example luminescence properties that are useful for explosive and metal ion sensing [38]. Other coordination polymers can serve as antimicrobial coatings for titanium-based implant materials [39] or for the detection of e.g. myoglobin [40]. A mixture of ligands, as used in the solvothermal reaction of 1,4benzene dicarboxylate $\left(\mathrm{H}_{2} \mathrm{BDC}\right)$ and 4,4'-dipyridyl-N,N'-dioxide (BPNO) with magnesium nitrate generates a porous framework able to selectively absorb and separate nitriles [41]. The bridging ligand 4,4'-(4-aminopyridine-3,5-diyl)dibenzoic acid ( $\left.\mathrm{H}_{2} \mathrm{APDA}\right)$ binds to magnesium ions via the carboxylic groups and the pyridine $\mathrm{N}$-atom to yield a luminescent sensor for pesticides, antibiotics and $\mathrm{Fe}^{3+}$ (Fig. 6) [42]. Zirconium-based MOFs with large enough pore size react with $\left[\mathrm{Mg}(\mathrm{OMe})_{2}(\mathrm{MeOH})_{2}\right]_{4}$ to yield $\mathrm{Mg}-$ doped MOFs that contain $\mathrm{MgZr}_{5} \mathrm{O}_{2}(\mathrm{OH})_{6}$ units (Fig. 5b) pointing

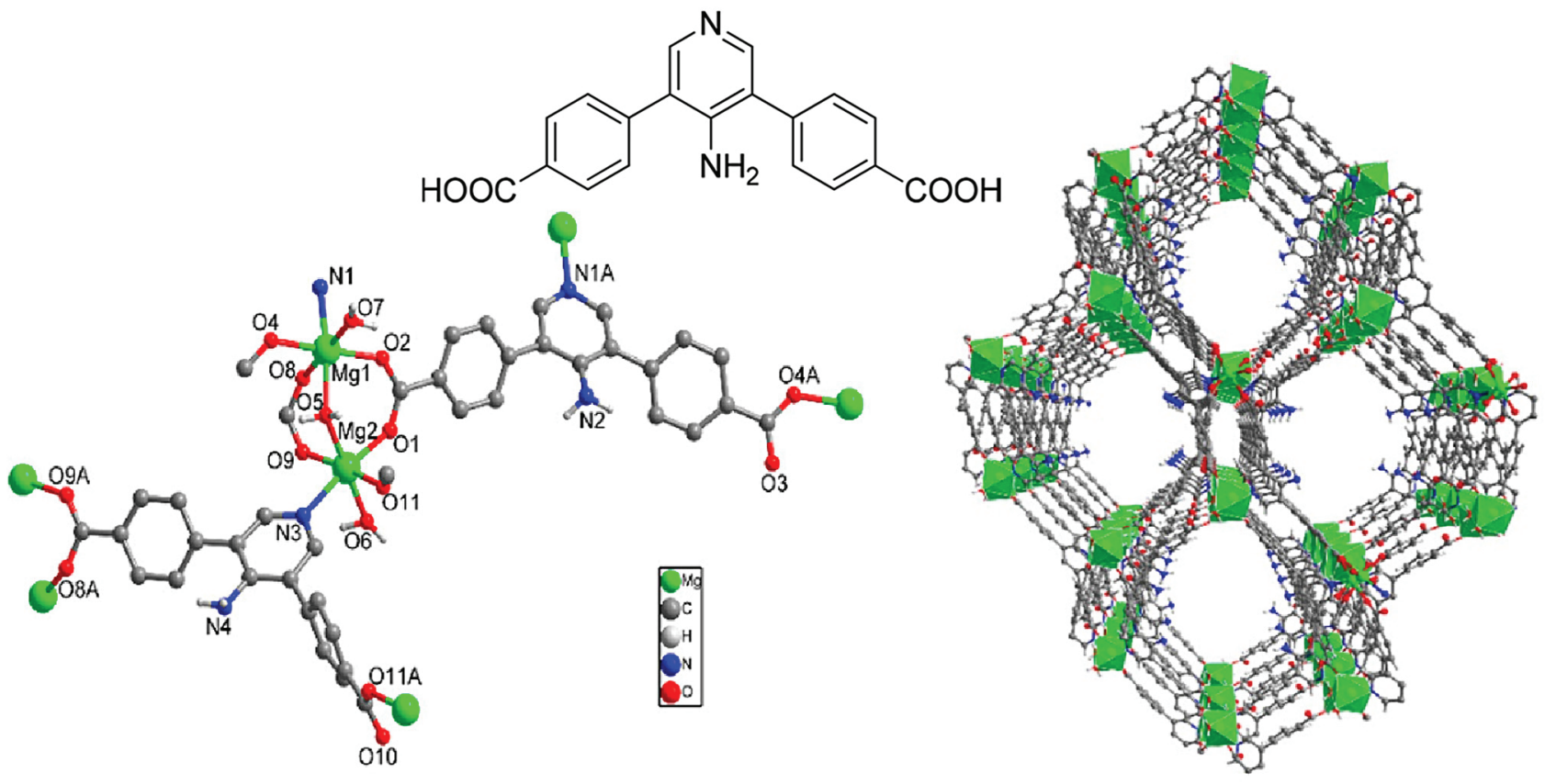

Fig. 6. Ligand $\mathrm{H}_{2} \mathrm{APDA}$ (top) and coordination of the deprotonated ligand to $\mathrm{Mg}^{2+}$ to yield the MOF-structure of $\left[\mathrm{Mg}_{2}(\mathrm{APDA})_{2}\left(\mathrm{H}_{2} \mathrm{O}\right)_{3}\right]$ (bottom) (adapted with permission from [42]). 

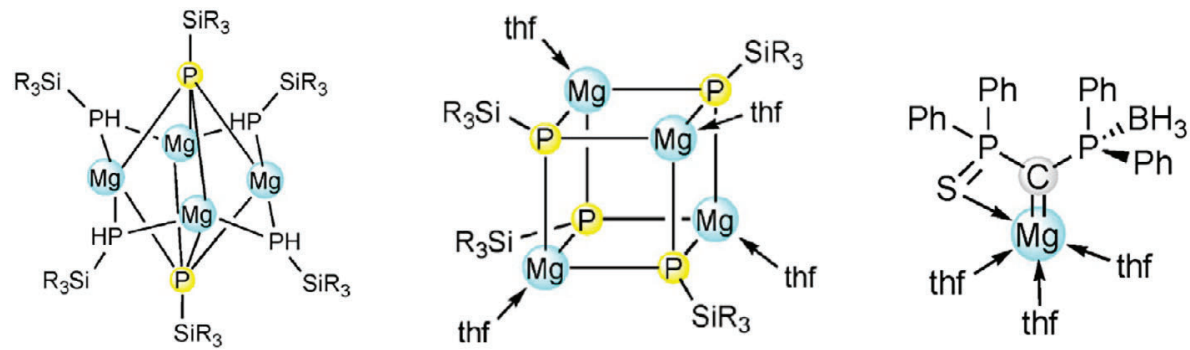

Fig. 7. Examples of ligand-shielded aggregates (left) versus solvent-shielded clusters (middle); $\mathrm{R}=\mathrm{tBu}$; Compound with formal magnesium-element double bond (right) (adapted with permission from [44]).

into the cavities, which was shown to enhance the catalytic activity toward the hydrolytic degradation of nerve agents by breaking of $\mathrm{P}-\mathrm{F}$ and P-S bonds [43]. The magnesium ion has then a coordination number of 8 .

A recent review highlights on the multiple interactions possible between magnesium (and the heavier alkaline earth metal) ions and main group fragments, leading to a large variety of cage compounds [44]. The alkaline earth metal ions then typically have a coordination number between 4 and 6 . The structural outcome of such aggregates depends often on the presence or not of O- or Ndonor solvents. In presence of donor solvents, these latter form the outer shell of the different aggregates and the metal ions point outward of their cage, while in the absence of donor solvent, the ligand plays the role of sterically shielding the cluster. Two such examples for magnesium are given in Fig. 7. The same publication discusses the possibility to formally obtain alkaline earth metal ion - element double bonds $[\mathrm{M}=\mathrm{E}]$ with alkylidenes, $\left(\mathrm{E}=\mathrm{CR}_{2}\right)$, imides $(E=N R)$, silylenes $\left(E=S_{2} R_{2}\right)$, and phosphandiides $(E=P R)$, although such multiple bond formalism does not describe its exact bonding nature (Fig. 7 , right).

\section{Calcium}

Magnesium and calcium are both essential elements in biology and their ions are therefore frequently considered as biocompatible. For instance, magnesium plays an important role in chlorophyll of plants as well as in our body as cofactor in numerous enzymes, it is essential for the synthesis of DNA, RNA and glutathione and our energy production. A normal adult human body contains roughly $1 \mathrm{~kg}$ of calcium, mostly as calcium apatite in the skeleton and teeth, but it also plays a major role as messenger ion, in blood clotting or muscle contraction. One of the famous calcium complexes in nature is certainly the oxygen-evolving center of photosystem II, in which one calcium ion is coordinated by up to eight O-donors and is integrated into a heterocubane-derived structure with manganese ions $[45,46]$. Chemists are challenged to mimic its structure and function and have come up with a number of similar complexes (Fig. 8), of which some recent ones are cited here $[47,48]$.

Like for beryllium and magnesium, the question arises whether low-valent states of calcium and other heavier alkaline earth metals can be generated. One such attempt was performed with $\mathrm{CO}$, which was coordinated to the heavy alkaline earth metal atoms, forming octa-carbonyl complexes $\mathrm{M}(\mathrm{CO})_{8}$ (Fig. 9), that could be isolated in a solid neon matrix and were shown and calculated to be similar to transition metal compounds by following the 18electron rule [49]. A strong red shift of the carbonyl stretching frequencies was observed and attributed to $\mathrm{M}-\mathrm{CO}$ bonds via [ $\mathrm{M}$ $\left.\left(d_{\pi}\right)\right] \rightarrow(C O)_{8} \pi$-backdonation. The bonding situation in these compounds is however currently controversially discussed as other authors claim ionic species like $\mathrm{Ca}^{2+}\left(\mathrm{CO}_{8}\right)^{2-}$ to be a more realistic

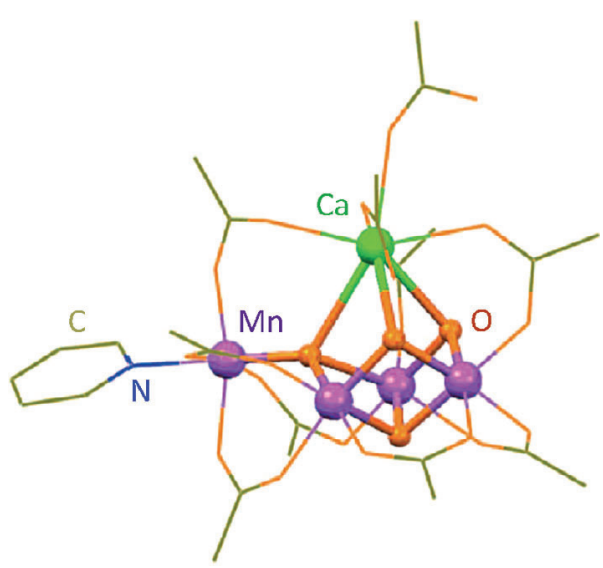

Fig. 8. Crystal structure of an artificial mimic of the oxygen-evolving $\mathrm{CaMn}_{4}$-cluster of photosystem II (inspired with permission from [47]).

description [50 a and b]. Along those lines, the isoelectronic dinitrogen ligand was used to recently generate the octa-coordinated metal-nitrogen compounds $\mathrm{M}\left(\mathrm{N}_{2}\right)_{8}$ for calcium, strontium and barium (Fig. 9) [51]. These highly reactive species were again trapped in a low-temperature solid neon matrix, and also follow the 18electron rule. Their spectroscopic analysis hints to a cubic symmetry and calculations indicate interactions based on $\left[\mathrm{M}\left(\mathrm{d}_{\pi}\right)\right] \rightarrow\left(\mathrm{N}_{2}\right)_{8}$ $\pi$-backdonation.

Monovalent calcium compounds (as well as of the heavier alkaline earth metals) could be identified mainly in the gas phase, e.g. monocyclopentadienyl compounds ( $\mathrm{CaCp}$ or SrCp, [52]) or monohalides like $\mathrm{CaCl}$ [53], although these might also stem from initial hydrides such as CaHX [100]. A highly unusual inverse sandwich complex based on monovalent calcium ions was obtained from the reaction of bromo-2,4,6-triphenylbenzene with activated calcium, yielding the highly reactive, black $\left[(\text { thf })_{3} \mathrm{Ca}\left\{\mu-\mathrm{C}_{6} \mathrm{H}_{3}-1,3,5-\right.\right.$ $\left.\mathrm{Ph}_{3}\right\} \mathrm{Ca}$ (thf) $)_{3}$ ] (Fig. 10) [54]. This compound features $\mathrm{Ca}-\mathrm{Ca}^{\prime}$ and $\mathrm{Ca}-\mathrm{C}$ distances of 4.27(3) and 2.59(3) Å, respectively, and is paramagnetic with a spin of $S=1$ (triplet) at $g=2.0023$ in ESR. The corresponding reaction with magnesium had led to a Grignard type compound, [(thf $\left.)_{2} \mathrm{Mg}(\mathrm{Br})-\mathrm{C}_{6} \mathrm{H}_{2}-2,4,6-\mathrm{Ph}_{3}\right]$. For the understanding of the bonding situation in the calcium complex, calculations, including dispersion, with different complexity and basis sets were carried out, and led to differing results, some of which fit well to the experimental values. Findings suggest that one electron is completely transferred from the $\mathrm{Ca}$ atoms onto the organic ligand, and that the HOMO-1 and HOMO-2 occupied molecular orbitals delocalized from one calcium atom via the aromatic ligand to the second metal ion with notable $d$-orbital contribution and overlap with the $\pi$-MOs of the arene ligand, leading to a partial charge on the calcium atom of 0.6 as confirmed via Löwdin population analysis [54]. 


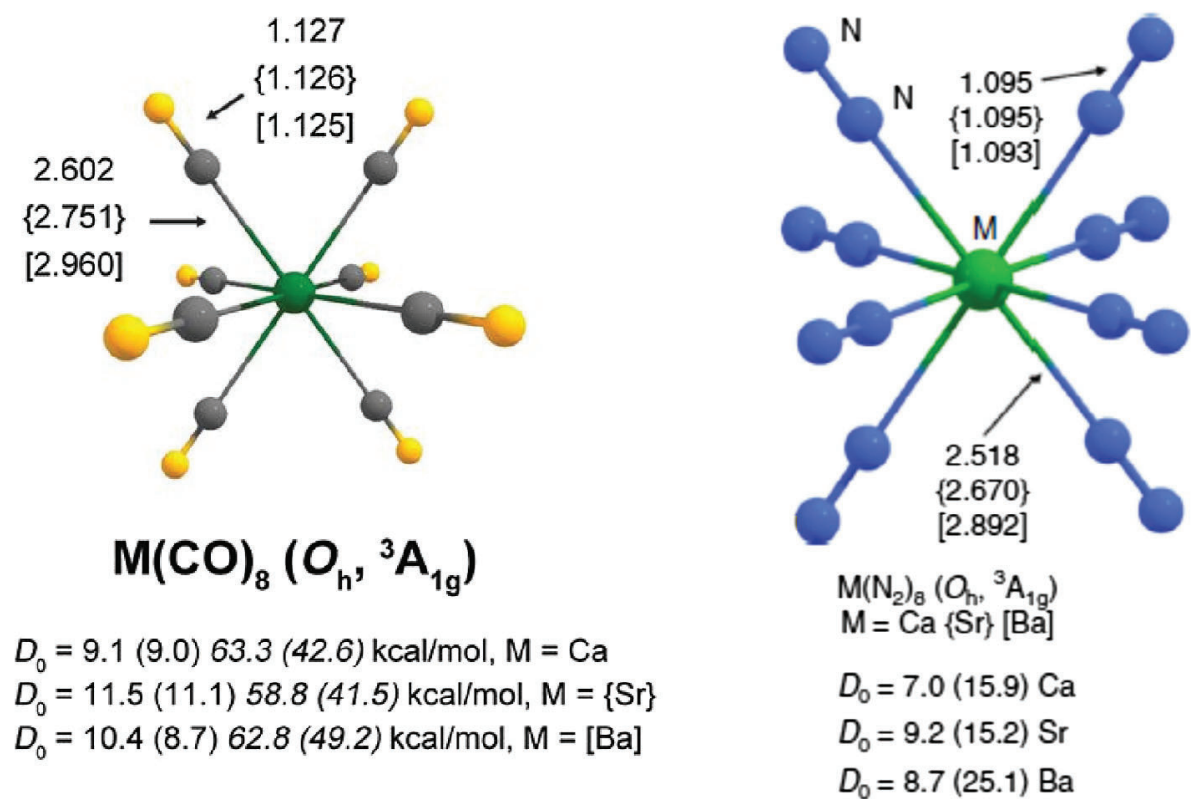

Fig. 9. The calculated structures of $\mathrm{M}(\mathrm{CO})_{8}$ (left) and $\mathrm{M}\left(\mathrm{N}_{2}\right)_{8}$ (right) obtained in a neon matrix (taken with permission from [49;51]).
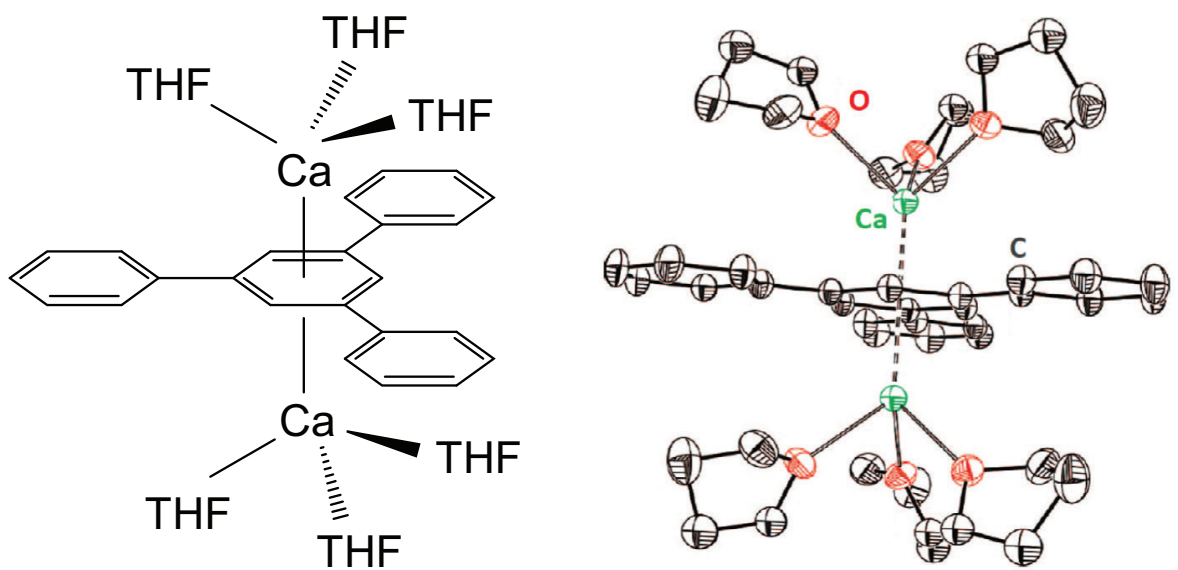

Fig. 10. Scheme and molecular structure of inverse organo-calcium compounds (adapted with permission from [54]).

$\mathrm{Ca}^{2+}$ ions (ionic radius $114 \mathrm{pm}$ ) are larger than $\mathrm{Mg}^{2+}$ ions $(86 \mathrm{pm})$, and favour therefore higher coordination numbers. Yet, the formation of calcium amides with coordination number three for the alkaline earth metal ion could recently be achieved in the absence of solvent, using ball milling to deliver the required activation energy [55].

Aromatic ligands, such as substituted cyclopentadienyl entities, are able to stabilize heavy alkaline earth metal alkyls as monomeric complexes and hydrides as dimers with THF as co-ligands. The dimeric forms with bridging hydride anions are reminiscent of the electron-deficient 3c-2e bonds described before in the chapter about beryllium. Formal coordination numbers of 3 in the monomers and 4 in dimers are thus realized for several examples of calcium compounds if taking into account only the number of ligands, while there are five, respectively six electron pairs contributing in total to the coordination (Fig. 11), and examples of strontium and barium complexes, all with coordination number 4 in terms of ligand number, are also given [56]. The poor coordination gives access to and infers a high reactivity of the hydrides towards alkene hydrogenation reactions.
Tetrahedral coordination is possible using sterically encumbered ligands, such as bulky formamidinate anions (Scheme 4) [57]. The excellent chemical reactivity and catalytic activity of heavy alkaline earth metal ion compounds with low coordination numbers using sterically encumbered ligands has been reviewed e.g. in 2010, highlighting the above type and other fascinating coordination compounds [58].

In analogy to magnesium, calcium is able to form a large number of different Grignard type compounds. It is however interesting that the direct synthesis of methyl calcium complexes in analogy to magnesium is not as simple and rather leads to the formation of Wurtztype coupling products $\mathrm{CaX}_{2}$ and $\mathrm{R}-\mathrm{R}$ [59]. Instead, a metathetical approach between LiMe and $\mathrm{Ca}\left\{\mathrm{N}\left(\mathrm{SiMe}_{3}\right)_{2}\right\}_{2}$ allowed to yield dimethylcalcium [60]. Heteroleptic alkylcalcium complexes could be prepared via insertion of 1 -alkenes into $\mathrm{Ca}-\mathrm{H}$ moieties of dimeric, hydride bridged calcium complexes described in Scheme 4 [61]. Further Grignard compounds of calcium and the heavier alkaline earth metals were recently collected and described in detail by Westerhausen et al., hence we refer the interested reader to this excellent overview [62]. Most of these organometallic compounds are stabi- 

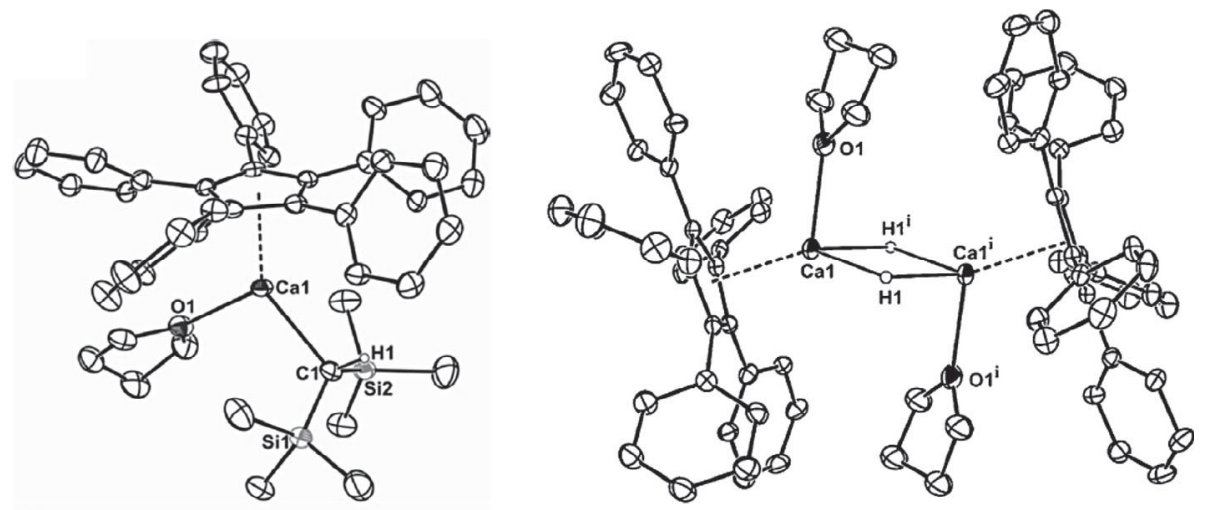

Fig. 11. Bulky cyclopentadienyl ligands stabilizing low coordination numbers for calcium ions (adapted with permission from [56]).

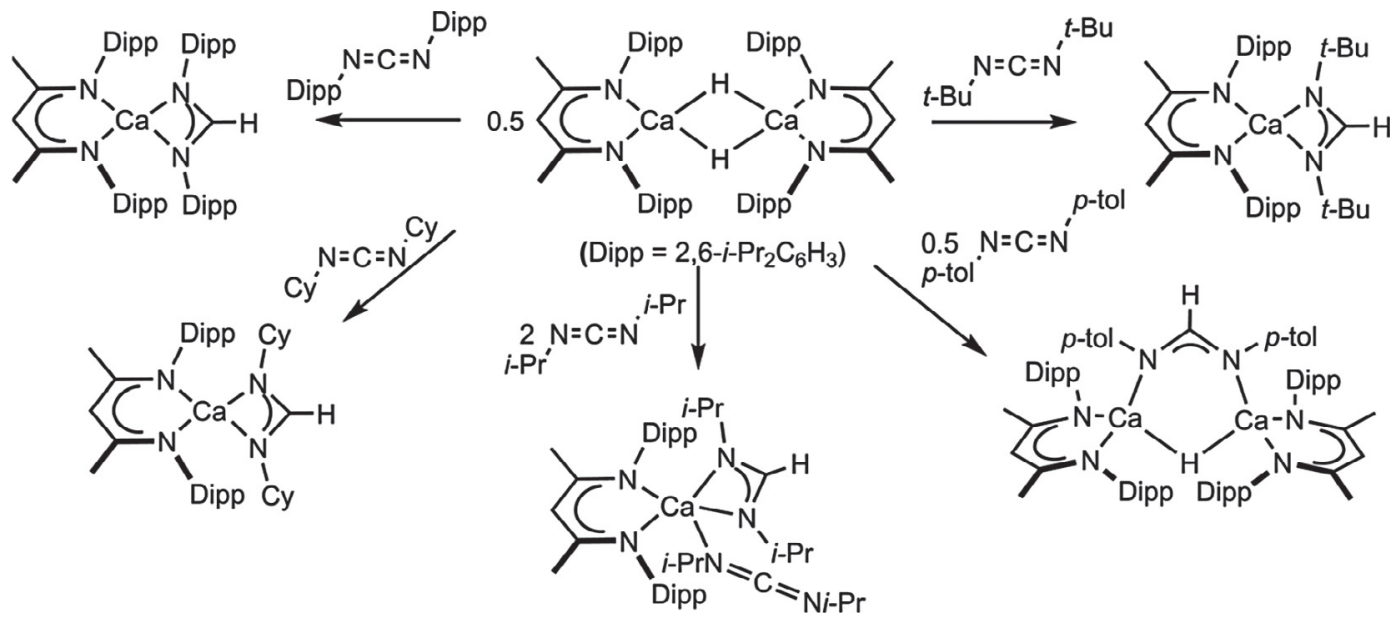

Scheme 4. Coordination compounds of calcium with coordination number 4 or 5, stabilized by bulky N-donor ligands (Scheme with permission from [57]).

lized by neutral donor ligands such as THF, with a typical overall coordination number of 6 . The review also shows that only few examples of strontium and barium Grignard compounds are known.

$\mathrm{N}$-donors that are substituted with fluorine-bearing organic residues may coordinate to alkaline earth metal ions by additional

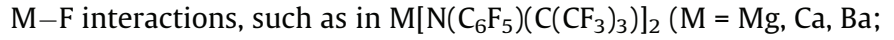
Scheme 5 left [63]; [Ca $\left.\left\{\mu-\mathrm{N}\left(\mathrm{SiMe}_{3}\right)_{2}\right\}\left\{\mathrm{N}\left(\mathrm{C}_{6} \mathrm{~F}_{5}\right)_{2}\right\}\right]_{2}$ (Scheme 5 right, [64]) or $\left[\mathrm{Ba}\left\{\mu-\mathrm{N}\left(\mathrm{C}_{6} \mathrm{~F}_{5}\right)_{2}\right\}\left\{\mathrm{N}\left(\mathrm{C}_{6} \mathrm{~F}_{5}\right)_{2}\right\} \text {.toluene }\right]_{2}$ [64]. While the formal coordination number with respect to $\mathrm{N}$-donors would be as low as 2 for magnesium or 3 for calcium, the fluorine atoms add to the stabilization of the metal ion coordination sphere, reaching coordination numbers 5-6.

Five-coordinate guadinate calcium complexes stabilized with bis-trimethylsilylamide and THF-donor ligands were shown to be useful catalysts, e.g. in hydroamination reactions and could compete with analogous zinc compounds [65].

Bulky O-donor ligands are also able to stabilize calcium (and other alkaline earth metal ions) ions with low coordination numbers, for example in the series of $\left[\mathrm{IM}(\mathrm{OtBu})_{4}\{\mathrm{Li}(\mathrm{thf})\}_{4}(\mathrm{OH})\right] \mathrm{com}-$ plexes (Fig. 12), in which for all heavier alkaline earth metal ions

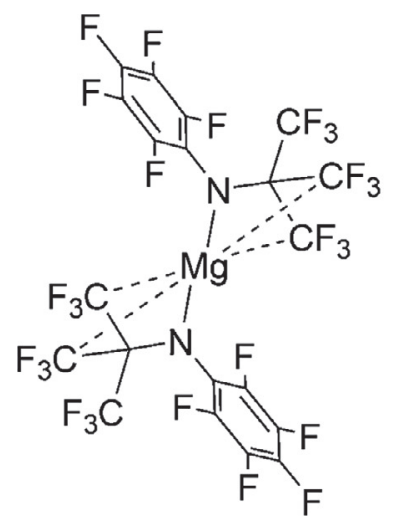

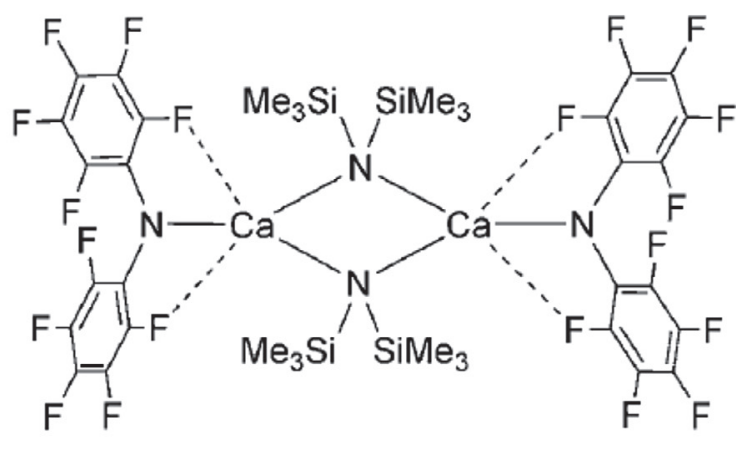

Scheme 5. Monomeric $\mathrm{Mg}\left[\mathrm{N}\left(\mathrm{C}_{6} \mathrm{~F}_{5}\right)\left(\mathrm{C}_{(}\left(\mathrm{CF}_{3}\right)_{3}\right)\right]_{2}$ and dinuclear $\left[\mathrm{Ca}\left\{\mu-\mathrm{N}\left(\mathrm{SiMe}_{3}\right)_{2}\right\}\left[\mathrm{N}\left(\mathrm{C}_{6} \mathrm{~F}_{5}\right)_{2}\right\}\right]_{2}$ [adapted with permission from 64]. 


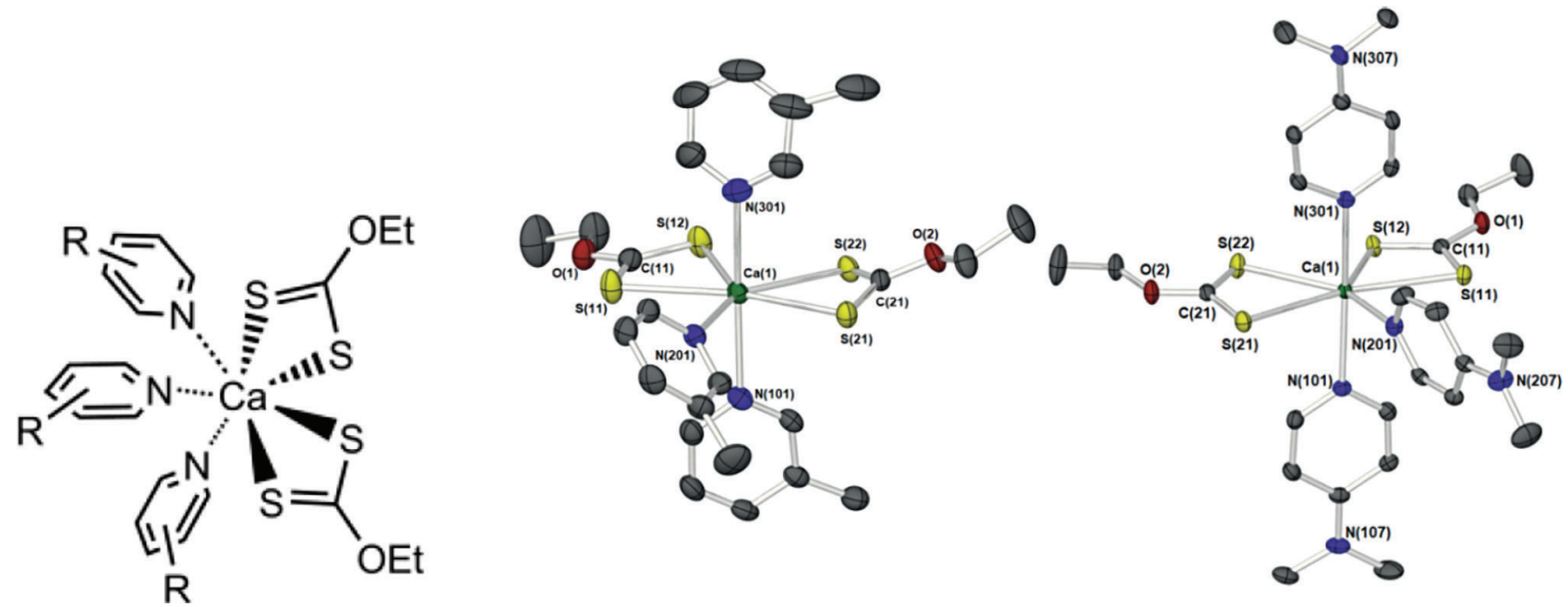

Fig. 14. Heptacoordinated calcium xanthate compounds with pyridine-derived co-ligands can act as precursors for CaS (with permission from [72]).
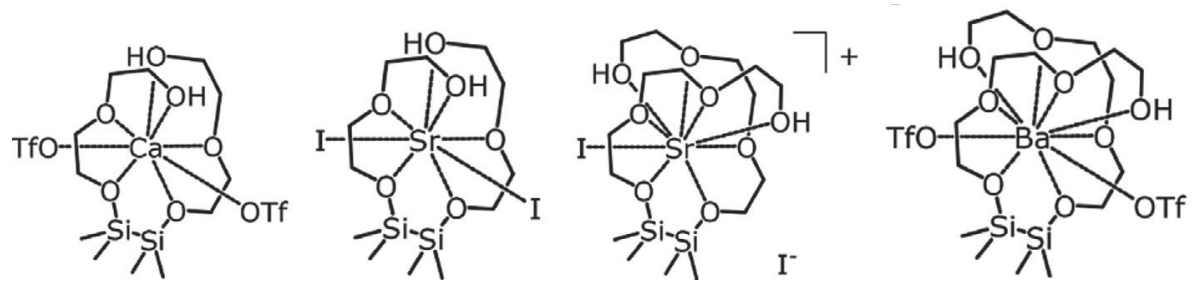

Scheme 6. Disila polyether complexes with $\mathrm{Ca}^{2+}, \mathrm{Sr}^{2+}$ and $\mathrm{Ba}^{2+}$ (adapted with permission from [73]).

tronegativity difference between the larger alkaline earth metals and the heavy halogens like iodine are smaller than 2 , hence are in the range for a covalent, very polar bond. The non-linearity of the axial I-M-I or TfO-M-OTf motifs in these compounds may be related to the observation that the molecular alkaline earth metal halides are rarely linear in the gas phase. This will be discussed in the chapter for barium. Total coordination numbers reach 8 on calcium, 8 or 9 for strontium and 10 for barium in this particular set-up.

Mixed-metal compounds in which alkaline earth metal ions are coordinated by metallo-ligands, hence ligands that already contain another metal ion, can be interesting for example in the context of catalysis and as precursors for mixed metal oxide materials, but also to stabilize low coordination numbers. Thus, an example for five-coordinate calcium ions is obtained by using tetraalkylaluminates or -gallates as ligands for calcium in presence of scorpionate-type co-ligands, leading to mixed-metal compounds with a high reactivity (Fig. 15) [74].

When metallic calcium is reacted with $[\mathrm{LGeCl}](\mathrm{L}=2,6-(\mathrm{CH}=$ $\left.\mathrm{NAr})_{2} \mathrm{C}_{6} \mathrm{H}_{3}, \mathrm{Ar}=2,6-\mathrm{iPr}_{2} \mathrm{C}_{6} \mathrm{H}_{3}\right)$, a dianionic radical species $[\mathrm{LGe}]^{2-}$ is formed, which itself coordinates to the produced calcium ions to yield a penta-coordinated calcium complex (Fig. 16) [75].
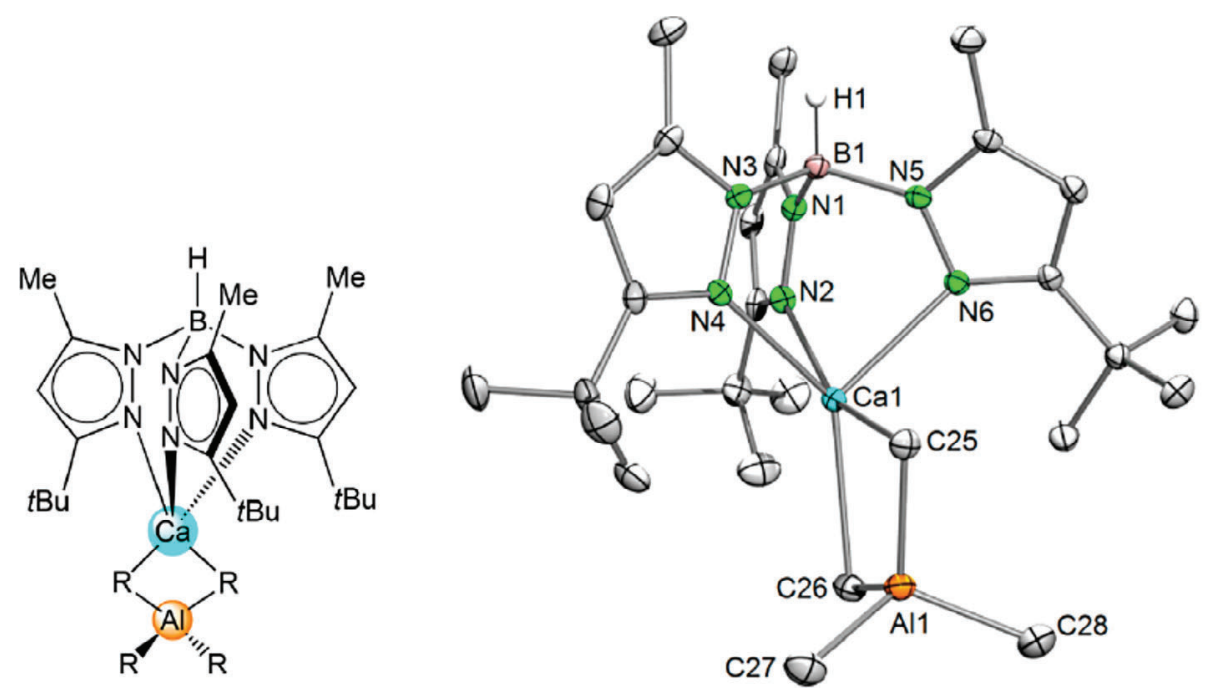

Fig. 15. Scorpionate-type bulky ligands are able to stabilize tetraalkylaluminate (and -gallate) calcium complexes ( $R=\mathrm{Me}$, Et) (with permission from [74]). 


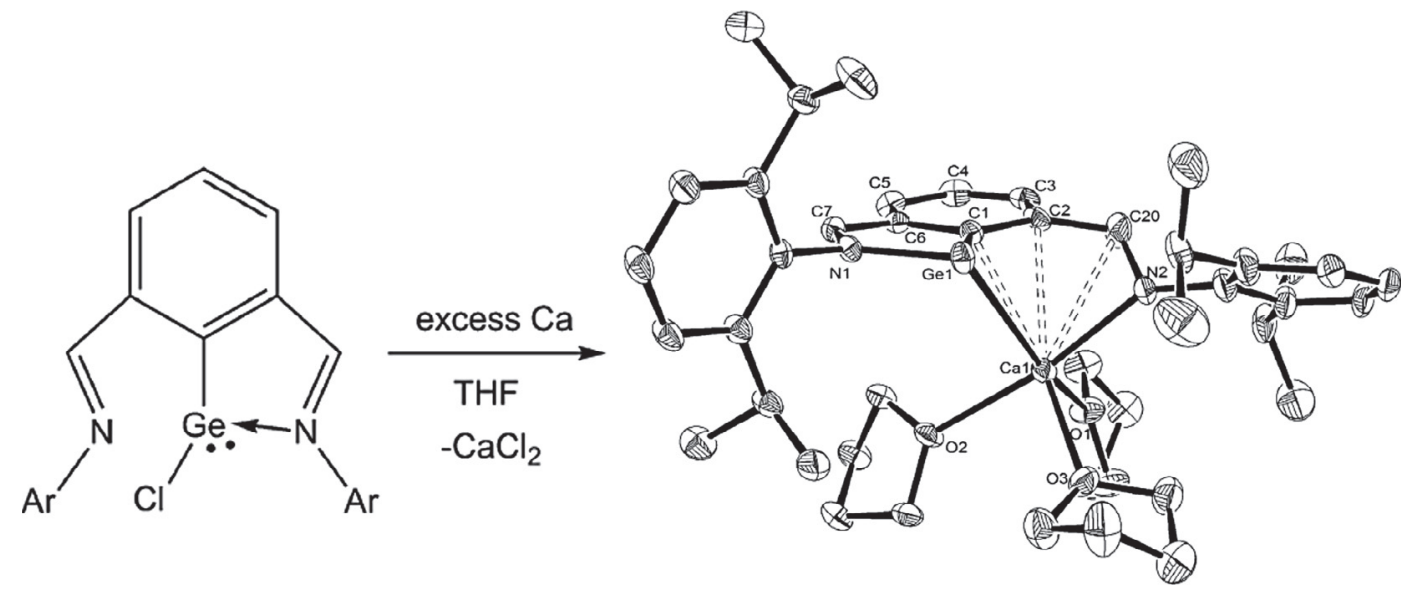

Fig. 16. Synthesis and molecular structure of the radical species $[\mathrm{LGe}]^{2-} \cdot \mathrm{Ca}(\mathrm{THF}) 3^{2+}($ adapted with permission from $[75])$.

Some other examples of such heterobimetallic species comprise the coordination polymers $\left\{\left[\mathrm{CaCr}_{2}(\text { pyim })_{2}\left(\mathrm{C}_{2} \mathrm{O}_{4}\right)_{4}\right] \cdot 2 \mathrm{MeOH}\right\}_{\mathrm{n}}$, $\left\{\left[\mathrm{SrCr}_{2}(\mathrm{dpa})_{2}\left(\mathrm{C}_{2} \mathrm{O}_{4}\right)_{4}\right] \cdot 8 \mathrm{H}_{2} \mathrm{O}\right\}_{\mathrm{n}}$, or $\left\{\left[\mathrm{BaCr}_{2}(\text { bipy })_{2}\left(\mathrm{C}_{2} \mathrm{O}_{4}\right)_{2}\left(\mathrm{H}_{2} \mathrm{O}\right)_{2}\right]\right.$. $\left.4 \mathrm{H}_{2} \mathrm{O}\right\}_{\mathrm{n}}($ pyim $=$ pyim $=2$-(2'-pyridyl $)$-imidazole, bipy $=2,2^{\prime}$-bipyri dine, $\mathrm{dpa}=\mathrm{dpa}=2,2^{\prime}$-dipyridylamine) [76]. Yet other copper- and nickel-metalloligands obtained with salen-derivatives form coordination polymer, respectively molecular entities depending on the size alkaline earth metal ion [77]. A recent review further highlights the effect of alkali metal ions on organometallic compounds, including the ones of the alkaline earth group [78].

Molecular as well as polymer trifluoroacetate compounds were -obtained mixing alkali and alkaline earth metal ion carbonates in

the presence of trifluoroacetic acid. The resulting heterometallic compounds were shown to yield the mixed metal fluorides upon heating [79].

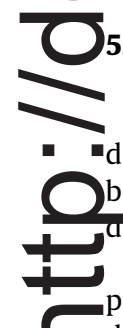

\section{Strontium}

As described earlier for calcium, strontium ions with low coordination numbers can be stabilized as well using steric and $\pi$ bonding encapsulation, e.g. with aryl-substituted and sterically demanding triazenes or heteroleptic aminotroponiminate $[80,81]$. Famous examples are the cyclopentadienyl double-decker compounds $\mathrm{MCp}_{2}$, which are bent for $\mathrm{M}=\mathrm{Ca}, \mathrm{Sr}, \mathrm{Ba}$ [82], and the tripledecker compounds with general formula $\left[\left(\mathrm{C}_{5} \mathrm{HR}_{4}\right) \mathrm{M}\left(\mu, \eta^{8}: \eta^{8}-\mathrm{C}_{8} \mathrm{H}_{8}\right)\right.$ $\left.\mathrm{M}\left(\mathrm{C}_{5} \mathrm{HR}_{4}\right)\right]$ with $\mathrm{R}=\mathrm{CHMe}_{2}$ and $\mathrm{M}=\mathrm{Ca}, \mathrm{Sr}, \mathrm{Ba}$, in which the metal ions possess a coordination number of 2 referring to the number of ligands ( 7 with respect to electron pairs) [83]. For the magnesium compound, it seems that the $3 d$ orbitals of magnesium lie too far above the $3 s$ and $3 p$ functions to contribute significantly to the bonding, while for calcium, the $3 d$ orbitals can contribute as they are closer to the $4 \mathrm{~s}$ orbital. In all cases, the bending and the bond types are explained by mainly ionic bonding but also a contribution of the in principle empty $d$-orbitals of the metal ions which can lead to a $\pi$-overlap with ligand orbitals [82] as shown in more quantitative detail for the next example below.

Indeed, the "exotic" ligand numbers 3 and 4 were realized for calcium, respectively strontium again with cyclooctatetraenyl as middle ligand in an inverse sandwich type complex, but now with an amido moiety and THF as terminal co-ligands on the metal ions (Fig. 17) [83,84]. Electrons are transferred from the metal to the organic cyclooctatetraene, resulting in the latter forming a biradical. Calculations trying to describe the interactions between the alkaline earth metal and the cyclic ligand gave a natural population analysis (NPA) partial charge of 1.83 for Ca and 1.86 for Sr in [M$\left.\left(\mathrm{C}_{8} \mathrm{H}_{8}\right)-\mathrm{M}\right]^{2+}$ fragments and orbital occupations of $4 s^{0.02} 3 d^{0.16}$ for Ca and $5 s^{0.02} 4 d^{0.13}$ for Sr. Calculations also included barium, and it was found that the ionic character of the interaction increases from Ca to its heavier congeners, that the $\delta$-interaction diminishes from $\mathrm{Ca}$ to $\mathrm{Ba}$ analogues, whereas the extent of $\pi$-interaction increases in the same order [85].

More examples are shown in the review on catalytic properties of the heavier alkaline earth metal compounds, including complexes with $\mathrm{N}$-heterocyclic carbenes, triazenide, aminotropiniminate, tris (imidazolin-2-ylidene-1-yl)borate and cyclopentadienylderived ligands [86].
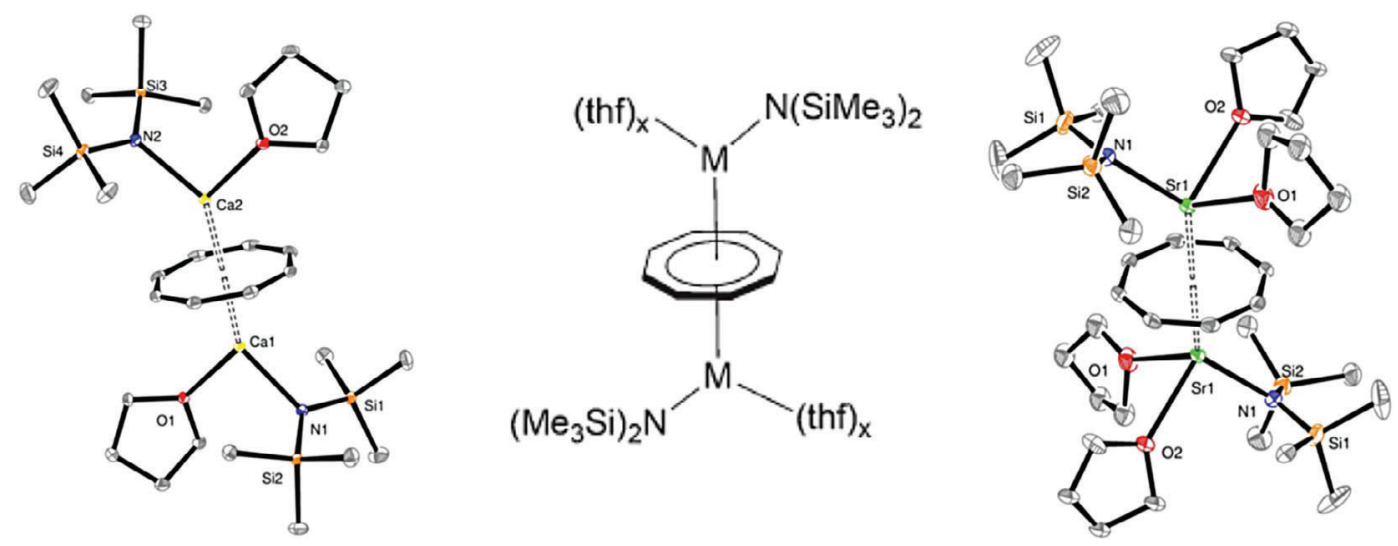

Fig. 17. Calcium (left) and strontium (right) complexes obtained with the cyclooctatetraenyl ligand (adapted with permission from [83]). 
The sterically highly demanding $\beta$-diketiminate ligand ${ }^{\text {DIPeP}} \mathrm{BDI}$ $\left(\mathrm{CH}[\mathrm{C}(\mathrm{Me}) \mathrm{N}-\mathrm{DIPeP}]_{2}\right.$, DIPeP $=2,6$-diisopentylphenyl $)$ was used not only with calcium, but also with strontium to stabilize hydride and alkyl complexes of strontium with low coordination numbers and high reactivity (Scheme 7). Similarly as for beryllium and magnesium, bridging hydride anions indicate the formation of $3 c-2 e$ bonds [87]. These compounds do not only possess beautiful structures, but act also as catalysts in the nucleophilic substitution of e.g. benzene.

Using the $\beta$-diketiminato ligand $\mathrm{L}=\mathrm{CH}\left(\mathrm{CMe}-2,6-\mathrm{iPr}_{2} \mathrm{C}_{6} \mathrm{H}_{3} \mathrm{~N}\right)_{2}$ has led to penta- and hexacoordinated strontium ions in a hydrocarbon-soluble, dinuclear fluoride or chloride complex [LSr(thf) $(\mu-\mathrm{X})_{2} \operatorname{Sr}(\text { thf })_{2} \mathrm{~L}$ ], X = F, Cl (Fig. 18) [88].

In other dinuclear complexes, the more common coordination number 6 is reached for the strontium ions, using $\mathrm{N}$ - and $\mathrm{O}-$ donor ligands such as aminoalkoxides and 2,2,6,6-tetramethyl-3, 5-heptanedionate (tmhd) [89]. The less sterically demanding these ligands were, the higher nuclearity of the final compound could be reached, i.e. the tetranuclear, heterocubane-type $[\operatorname{Sr}(\mathrm{dmapmp})$ (tmhd) $]_{4}$, where dmapmp $=1$-(3-(dimethylamino)propoxy)-2-me thylpropan-2-olate [89]. Hexanuclear strontium hydride clusters were recently isolated with stabilizing $\mathrm{N}$-donor ligands and shown to possess a coordination number of 6 to 8 (Fig. 19 left) [90]. The largest aggregate of strontium ions with coordination number 6 probably still is the $\mathrm{Sr}_{12}$-compound (Fig. 19, right) in which two hexanuclear entities are linked via an iodide anion [66]. A comparison of both structures show a hydride, respectively oxide in the centre of the octahedral structures formed by six strontium ions. The octahedral coordination sphere around each strontium ion is in both cases heavily distorted.

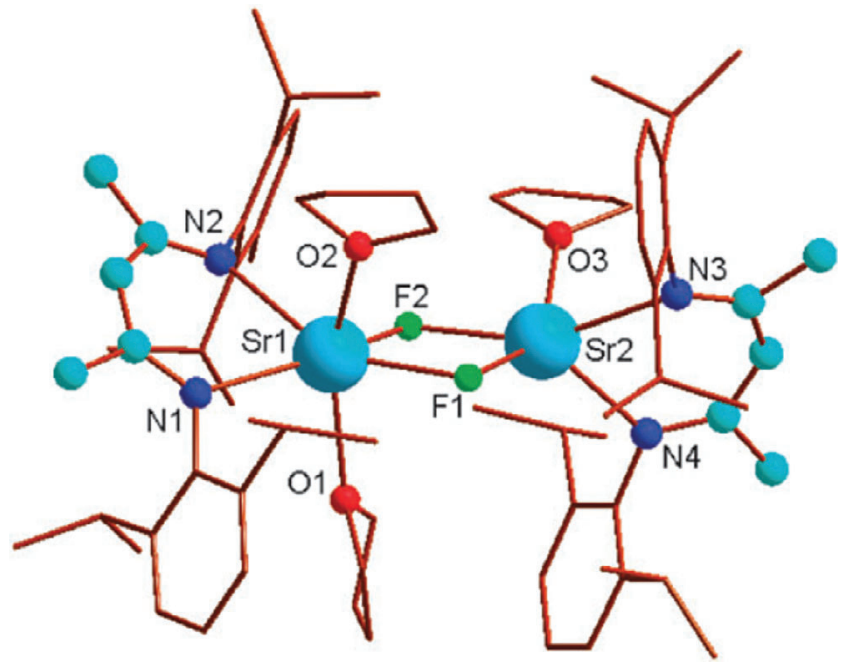

Fig. 18. Dinuclear complex of $\mathrm{Sr}^{2+}$ with penta- and hexacoordination (Image taken with permission from [88]).

In the literature, other similitudes between alkaline earth halide or alkoxide or aryloxide coordination compounds can be found, as exemplified in the strontium clusters based on either iodide- or aryloxide-bridged $\mathrm{Sr}^{2+}$-triangles (Fig. 20) [91,92].

In coordination polymers of strontium, the coordination number varies, depending on the size and shape of the ligands, while solvent molecules such as water, alcohol or amines are typically found to fill free coordination sites. Ligands based on carboxylate

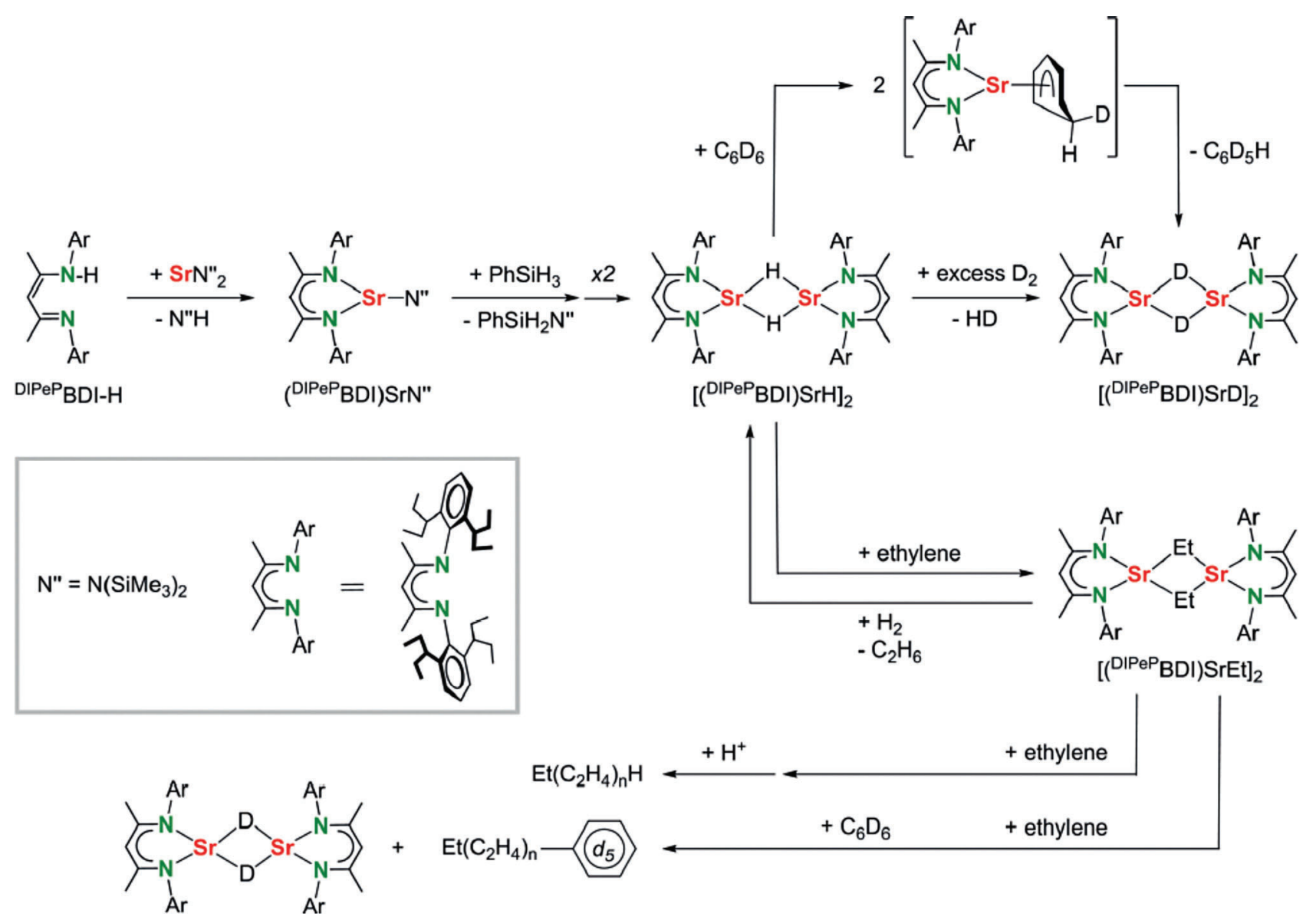

Scheme 7. Synthesis and reactivity of strontium hydride and alkyl complexes (taken with permission from [87]). 

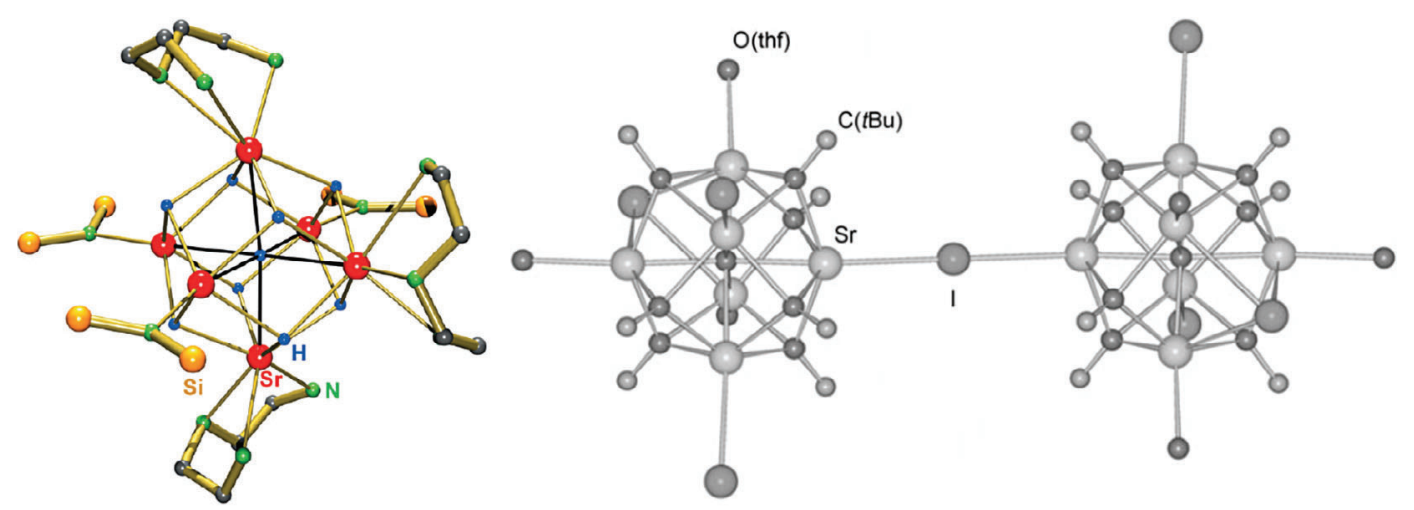

Fig. 19. Hexanuclear strontium hydride complex (left, image with permission from [90]) and a $\mathrm{Sr}_{12}$-cluster (right, image with permission from [66]).
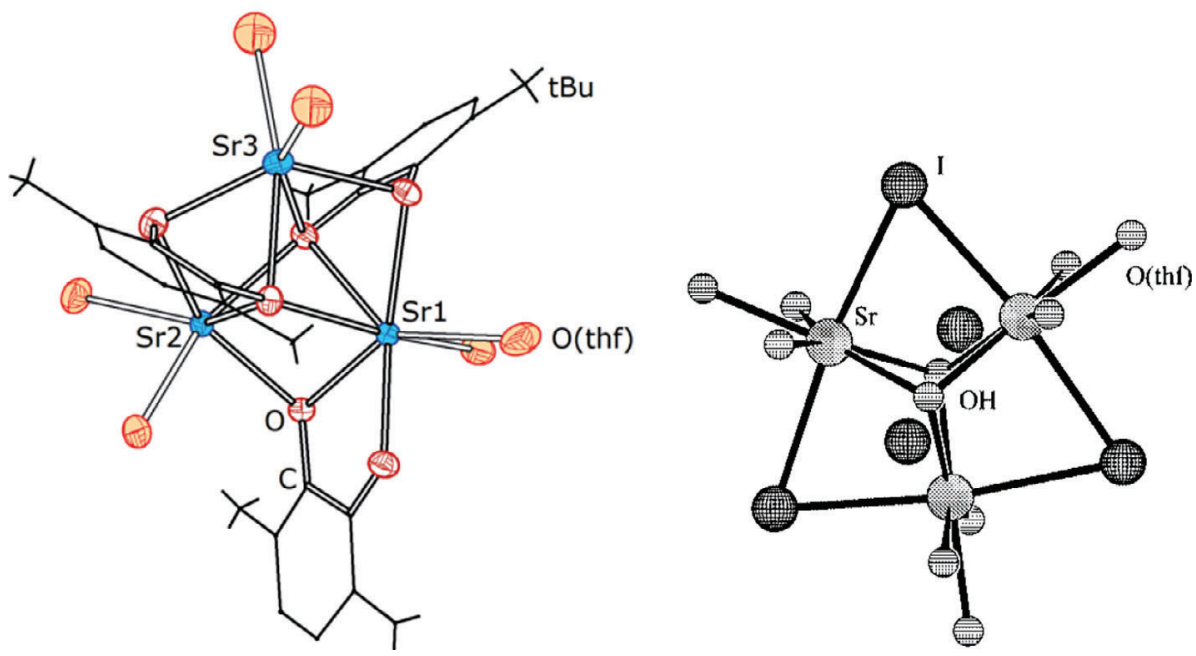

Fig. 20. Triangle-shaped $\mathrm{Sr}_{3}$-complexes with aryloxide (left) and iodide (right) as bridging ligands (with permission from [91] (right) and [92] (left))

donor groups have recently been reported to yield coordination numbers between 6 and 9 in two-dimensional and threedimensional frameworks based on strontium ions (Fig. 21) [93]. Given the many different possibilities to fill the coordination sphere of large, closed shell cations such as $\mathrm{Sr}^{2+}$ and $\mathrm{Ba}^{2+}$, it is however often tricky to predict the outcome and structure of a polymer structure.

Heptacoordination is quite frequently encountered for strontium as well as barium compounds, with geometries derived from a pentagonal bipyramid. The distortion is mostly due to the bite angles of chelating ligands, as exemplified in salen-type ligands with solvent molecules as co-ligands, such as in $[\operatorname{Sr}(\operatorname{salen}(t-B u))$ $(\mathrm{HOEt})_{3}$ ] [94]. P,N-donor ligands such as diphosphanylamide lead, in presence of coordinating THF-molecules, to a severe distortion of the geometry, as shown in Fig. 22. [95]. These examples show also the nice analogy of the heavy alkaline earth metal ions with divalent lanthanide complexes (see also ref. [66]).

An example of an octacoordinated $\mathrm{Sr}^{2+}$ is the two-dimensional coordination polymer obtained with the zwitterionic 1,3-bis(car boxymethyl)-imidazolium ligand (Fig. 23) [96]. It shows that the ligands have different binding modes, connecting either with one or two oxygen atoms of the carboxylate moieties. Furthermore, the sheet-type structure of the compound allows to intercalate an almost planar arrangement of water molecules.

Nona-coordinated strontium ions are for instance found in metal-organic frameworks using (tetrafluoro-)phthalic acid as main ligand and water as co-ligand [97].

\section{Barium}

Although magnesium has a higher density than calcium $\left(1.738 \mathrm{~g} / \mathrm{cm}^{3}\right.$ for magnesium versus $1.55 \mathrm{~g} / \mathrm{cm}^{3}$ for calcium), the literature cites the alkaline earth metals as of calcium and higher as the heavy group 2 metals.

As a metal, barium can, under pressure, adopt very complex structures that are difficult to determine. Only recently, the most complex of these crystal structures was solved, namely that of the phase Ba-IVc, which was obtained at $19 \mathrm{GPa}$. It turned out to be a commensurate host-guest structure with 768 atoms in the basic unit, and intertwined S-shaped $\mathrm{Ba}_{12}$-chains [98].

The halides of the heavier alkaline earth metals, in particular of calcium, strontium and barium gave rise to intense experimental and theoretical work, as there were hints that some $\mathrm{MX}_{2}$ molecules had a bent structure in the gas phase [99]. Results were however ambiguous as vibrations may give on average a linear structure. A review by Magdolna Hargittai from 2000 gives the (historic) details of the developments in this particular field [100]. From the valence shell electron pair repulsion (VSEPR) model, the alkaline earth metal halides are expected to be linear. In terms of hybridization, either $s p$ or $s d$ hybrids have been discussed, and only the $n s(n-1) d$ hybrid could lead to a bent structure. Polarizability was another factor discussed to explain the bending in $\mathrm{MX}_{2}$ structures. From computational studies, it could be shown that both, polarizability and (n-1) shell $d$-orbital participation were important to reach the correct structures. The choice of basis set is crucial 

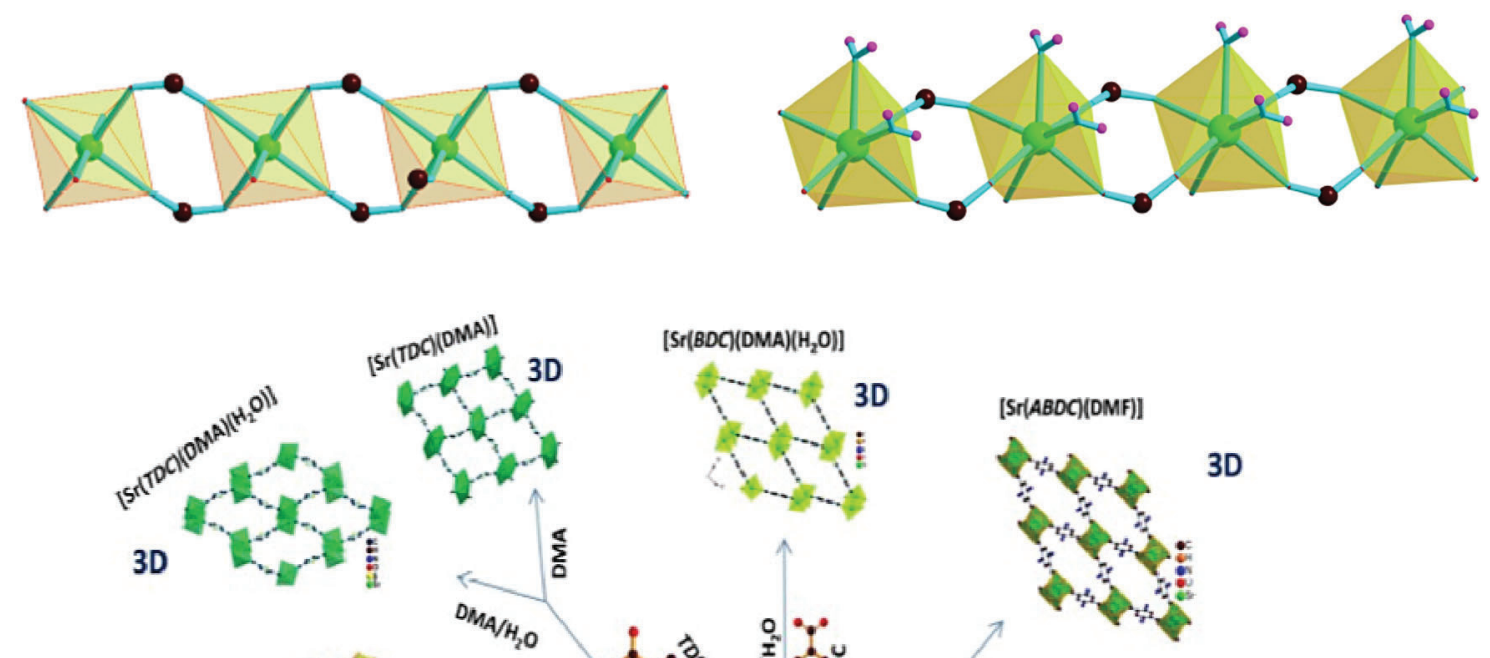

[Sr(BDC)(DMA)(H $\left.\left.\mathrm{H}_{2} \mathrm{O}\right)\right]$
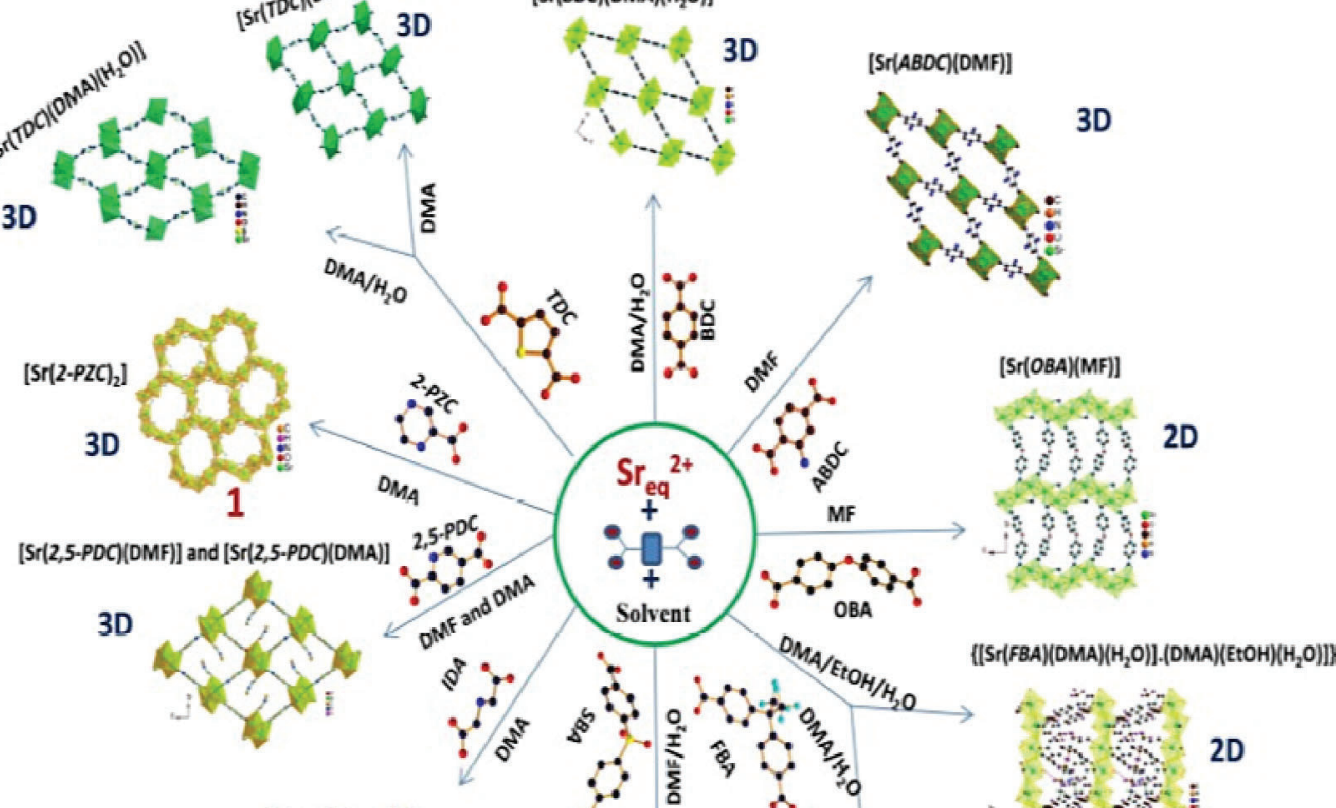

$2 \mathrm{D}$
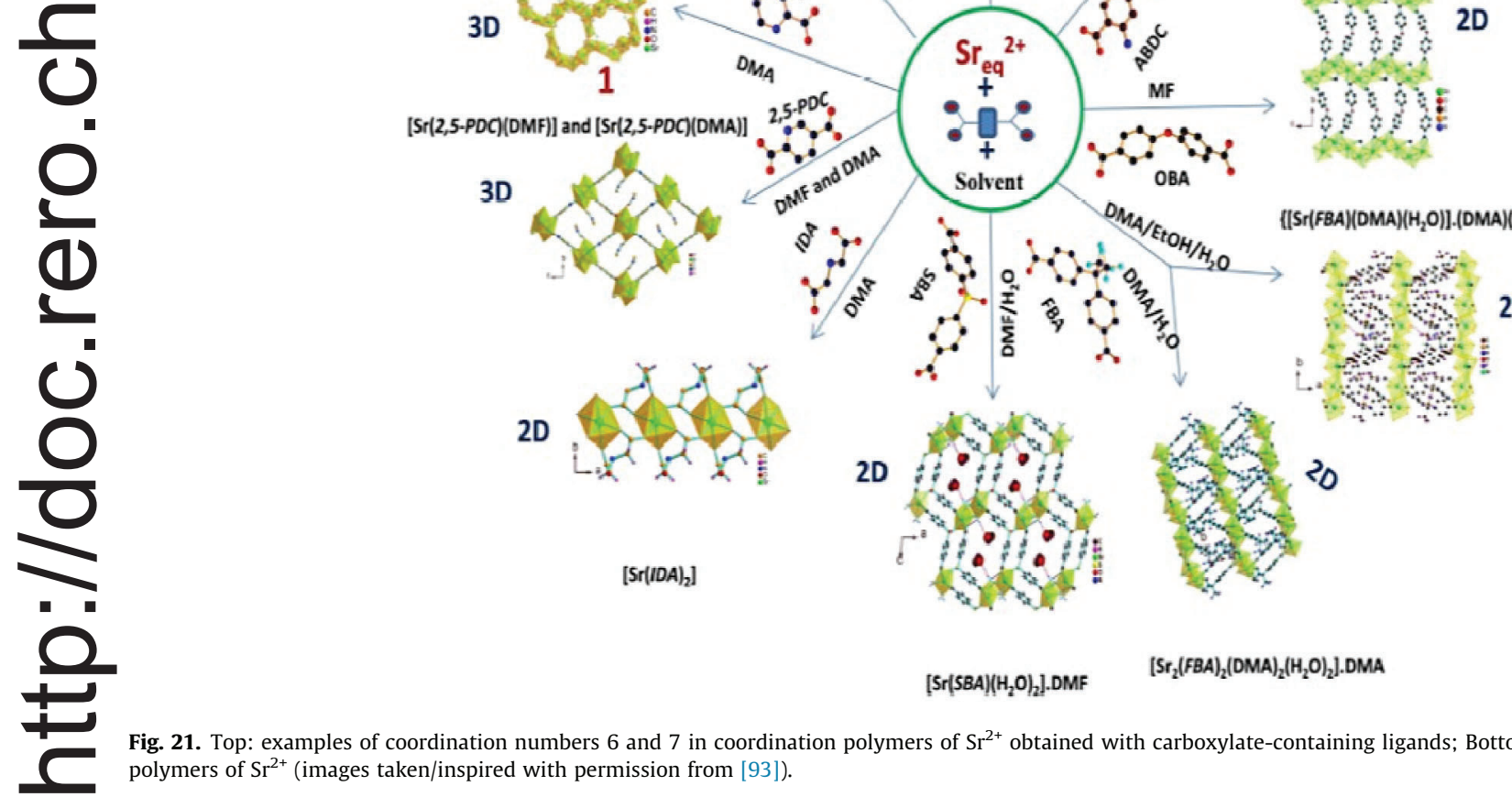

2D

2D
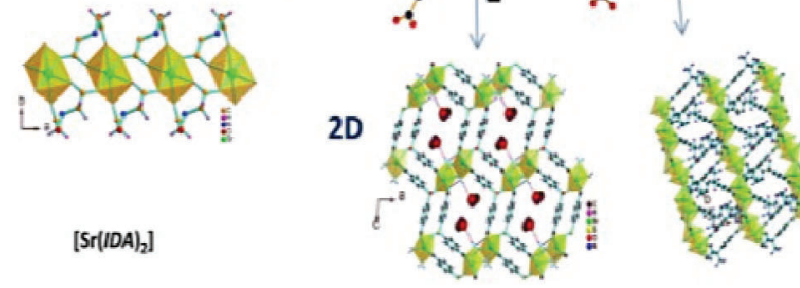

20

$\left[\mathrm{Sr}(\mathrm{SBA})\left(\mathrm{H}_{2} \mathrm{O}\right)_{2}\right] . \mathrm{DMF}$

$\left[\mathrm{Sr},(\mathrm{FBA})_{2}(\mathrm{DMA})_{2}\left(\mathrm{H}_{2} \mathrm{O}\right)_{2}\right] \cdot \mathrm{DMA}$

Fig. 21. Top: examples of coordination numbers 6 and 7 in coordination polymers of $\mathrm{Sr}^{2+}$ obtained with carboxylate-containing ligands; Bottom: panoply of coordination polymers of $\mathrm{Sr}^{2+}$ (images taken/inspired with permission from [93]).
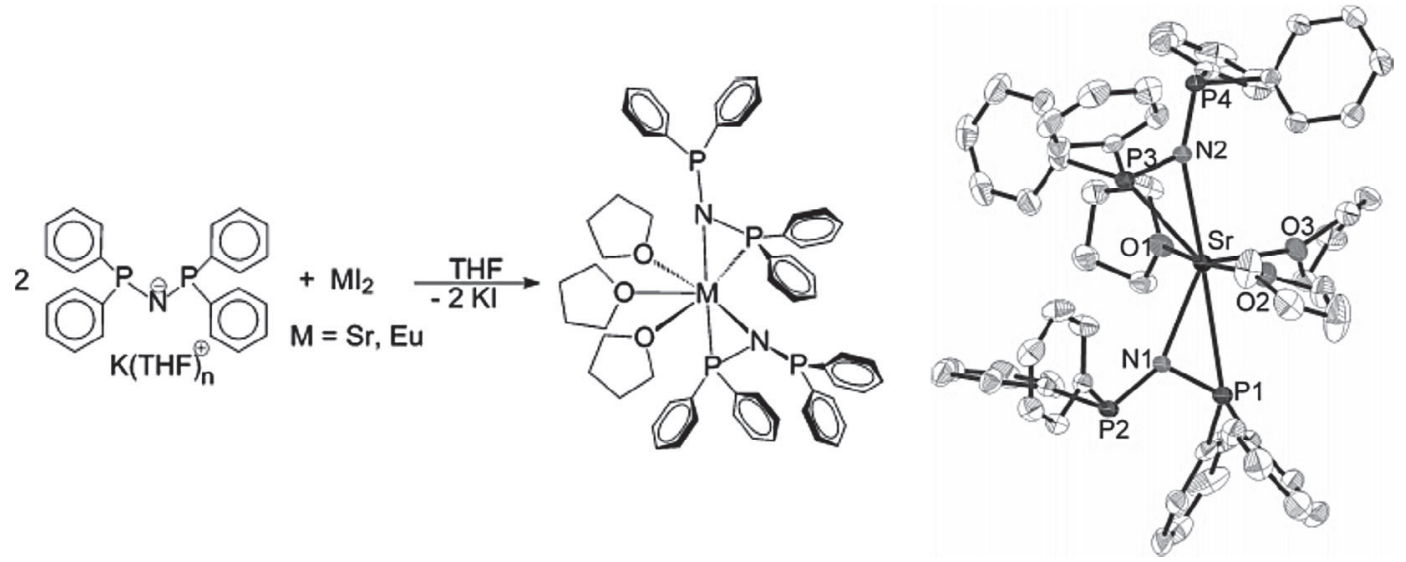

Fig. 22. Synthesis of bis(diphosphanylamido) complexes of strontium (and europium) (scheme and image taken with permission from [95]). 

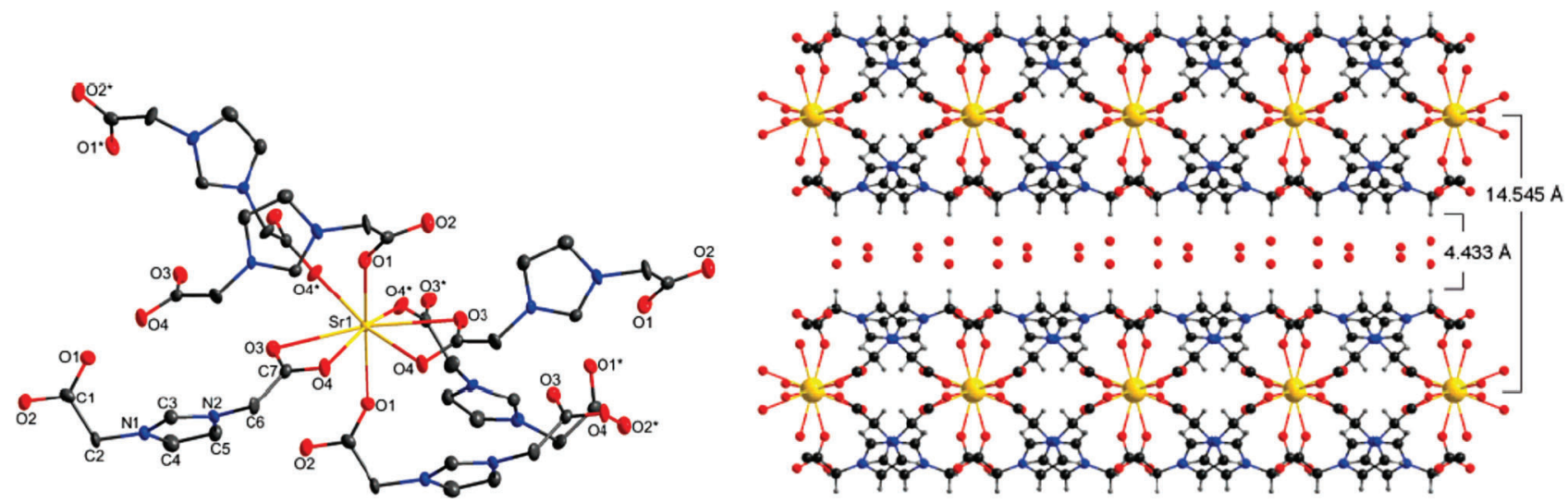

Fig. 23. Example of a layered coordination polymer (right) with 8-coordinated $\mathrm{Sr}^{2+}$ ions (left) (with permission from [96]).

Table 1

Calculated and experimental bond distances and angles for the alkaline earth fluorides and chlorides [100-102].

\begin{tabular}{llll}
\hline Molecule & $\mathrm{M}-\mathrm{X}(\AA)$ calc. & $\mathrm{M}-\mathrm{X}(\AA)$ exp. & $\mathrm{X}-\mathrm{M}-\mathrm{X}\left({ }^{\circ}\right) \mathrm{calc.}$ \\
\hline $\mathrm{CaF}_{2}$ & 2.013 & 2.1 & 157 \\
$\mathrm{CaCl}_{2}$ & 2.476 & 2.51 & 135 \\
$\mathrm{SrF}_{2}$ & 2.139 & $2.20 \pm 0.03$ & 180 \\
$\mathrm{SrCl}_{2}$ & 2.635 & $2.606-2.67$ & 136.4 \\
$\mathrm{BaF}_{2}$ & 2.246 & $2.32 \pm 0.03$ & 161.4 \\
$\mathrm{BaCl}_{2}$ & 2.761 & $2.82 \pm 0.03$ & 123.1 \\
\hline
\end{tabular}

(1)

to calculate the correct bond angle of $\mathrm{MX}_{2}$, and uncontracted $d$ polarization functions were recommended to obtain realistic bend-ing energies. For beryllium and magnesium, which do not possess

any close ( $\mathrm{n}-1) d$ orbitals, the dihalides are all linear. For calcium, all dihalides are found to be linear, except $\mathrm{CaF}_{2}$, for which an angle around $154^{\circ}$ was determined, yet with a low energy difference between the linear and bent geometry of roughly $1 \mathrm{~kJ} / \mathrm{mol}$. For the $\mathrm{MX}_{2}$ molecules that appear linear on average (quasilinear), the values for the bending energies are ca. $0.8 \mathrm{~kJ} / \mathrm{mol}$ for $\mathrm{SrCl}_{2}$, $<0.2 \mathrm{~kJ} / \mathrm{mol}$ for $\mathrm{SrBr}_{2}$ and ca. $1.7 \mathrm{~kJ} / \mathrm{mol}$ for $\mathrm{BaI}_{2}$. For unambiguously - bent molecules, like $\mathrm{SrF}_{2}, \mathrm{BaCl}_{2}$, or $\mathrm{BaBr}_{2}$, the barrier to linearity is below $8 \mathrm{~kJ} / \mathrm{mol}$, and only $\mathrm{BaF}_{2}$ was found to possess a bending energy of $25 \mathrm{~kJ} / \mathrm{mol}$. A very recent theoretical study resumes the geometry of the heavier alkaline earth metal halides and hydroxides, some of which are exemplarily resumed in Table 1 [101,102]. In water, most of the solid alkaline earth metal halides dissolve into ions, but in organic solvents such as tetrahydrofuran, the compounds can be dissolved as molecules and are stabilized with donor solvent molecules in equatorial positions, while the $\mathrm{X}$ $\mathrm{M}-\mathrm{X}$ moiety remains intact and is typically bent, as for instance in $\left[\mathrm{BaI}_{2}(\mathrm{THF})_{5}\right][99]$. Now, this could be argued as due to the asymmetric coordination of five THF molecules in equatorial positions, leading to the bending of the I-Ba-I entity. A solution to this problem could be the use of crown ethers. Barium ions have a similar ionic radius than potassium ions (152 pm) and hence fit perfectly into the cavity of 18-crown-6. This ligand can indeed be employed to coordinate to the cation occupying six equatorial positions. The coordination sphere of the barium cation is then typically completed by two anionic ligands in axial positions, resulting in the coordination number 8 , as for example in the metal-organic compound $\left[\mathrm{Ba}\left(\mathrm{CHPh}_{2}\right)_{2}\right.$ (18-crown-6)] (Fig. 24) [103].

Even now that the equatorial ligand is symmetrically distributed around the "belt", the axial ligands are not quite linear. This has been further investigated on behalf of alkaline earth metal acetylides, for which the classical VSEPR also fails [104]. The authors come to the conclusion that donor-acceptor interactions between the acetylinic moiety and the crown ether would be

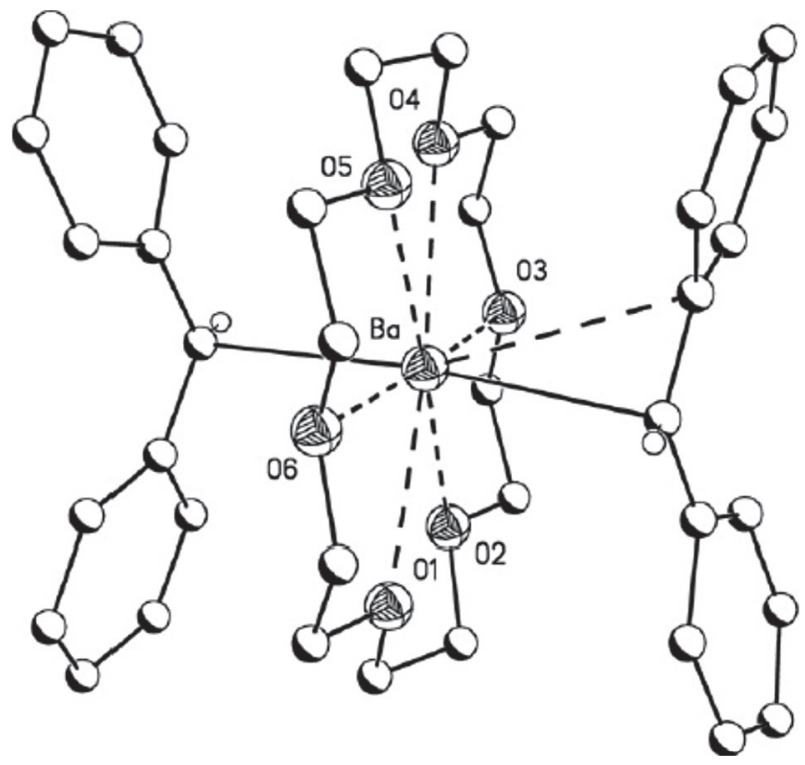

Fig. 24. Octacoordination of barium in $\left[\mathrm{Ba}\left(\mathrm{CHPh}_{2}\right)_{2}(18\right.$-crown-6)] (taken with permission from [103]).

responsible for the deviation from ideal geometry in the solid state analysis.

As such, the alkaline earth metal halides very much behave like transition metal halides in organic solvents, hence they do not dissociate and can be used to perform substitution reactions with group 1 metal compounds under salt elimination. Solid state structures of (mixed) halides of barium were recently published with typical coordination number 9 [105]. The gas phase iodides of the heavy alkaline earth metals further show a surprising bent structure, which is the most prominent for $\mathrm{BaI}_{2}$, for which it can be stabilized by coordination of neutral donor ligands like THF [106]. This behaviour is also observed for the transition metal 
halides, for which e.g.THF adducts are likewise known [107]. That the substitution of halide, in particular iodide can take place in a controlled manner has been recently studied with different strong O-donors [91,108]. Recent calculations on saturated barium halide vapors indicate the possible existence of different (charged) cluster entities with different barium:halide ratios (Fig. 25) [109,110].

In analogy to the bent gas phase structure of $\mathrm{BaI}_{2}$, lowcoordinate boryloxides of barium also possess coordination number 2 and a bent geometry, as exemplified in $[\mathrm{Ba}(\mathrm{OB}\{\mathrm{CH}$ $\left.\left.\left(\mathrm{SiMe}_{3}\right)_{2}\right\}_{2}\right)_{2}$ ] (Fig. 26) [111]. The THF-solvate of this compound has a coordination number of 4 , while the heteroleptic dimer [Ba $\left.\left\{\mu_{2}-\mathrm{N}\left(\mathrm{SiMe}_{3}\right)_{2}\right\}\left(\mathrm{OB}\left\{\mathrm{CH}\left(\mathrm{SiMe}_{3}\right)_{2}\right\}_{2}\right)\right]_{2}$ has a coordination number of 3 [111].

Metal-organic compounds of barium can be accessed by direct metalation of protonated ligand, producing hydrogen as side product, or by using metallic barium metal in excess and organic ligands of type HL, such as amine, cyclopentadiene, pyrazole or phenol, in presence of triphenyl bismuth [112]. This second method generates metallic bismuth and benzene as side products and is called redox transmetalation protolysis.

Being also the softest alkaline earth metal cation with the lowest charge density, barium is easily polarizable and interacts also with aromatic systems in a cation- $\pi$ interaction [113] or via weak contacts with alkyl H-atoms (Fig. 27).

As for the other alkaline earth metal ions, low coordination numbers for barium can also be stabilized with bulky ligands, often amides. However, since barium is the largest non-radioactive cation in the family with $149 \mathrm{pm}$ radius, the ligands need to be "superbulky", like the $\beta$-diketiminate ligand ${ }^{D I P e P} \mathrm{BDI}(\mathrm{CH}[\mathrm{C}(\mathrm{Me}) \mathrm{N}$ $\mathrm{DIPeP}]_{2}, \mathrm{DIPeP}=2,6$-di-isopentylphenyl) (Fig. 28). This ligand is able to cover half of the coordination sphere, leaving the other half for a bis(trimethylsilyl)amide entity. Compared to barium amides with smaller ligands, this coordination compound is stable in solution over several weeks and at temperatures up to $140{ }^{\circ} \mathrm{C}$ [113]. (a)
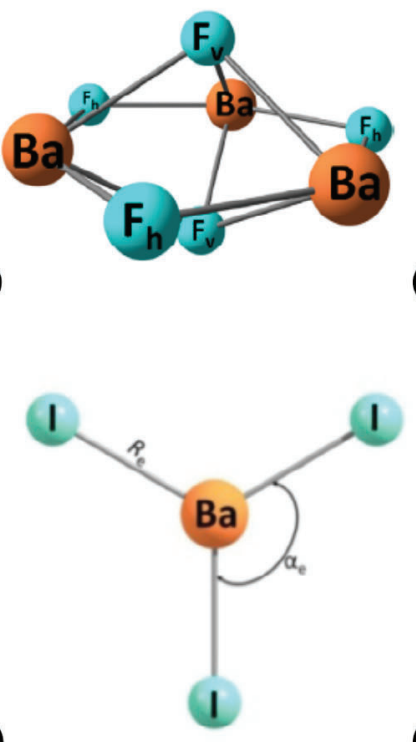

(b)
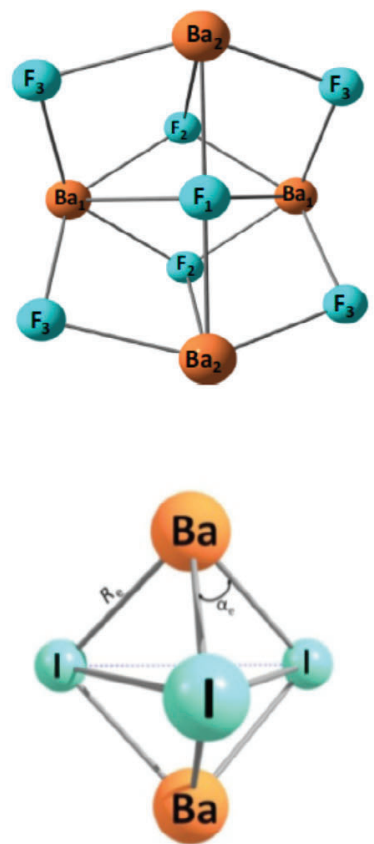

(c)

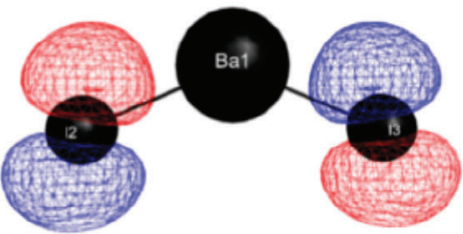

(f)

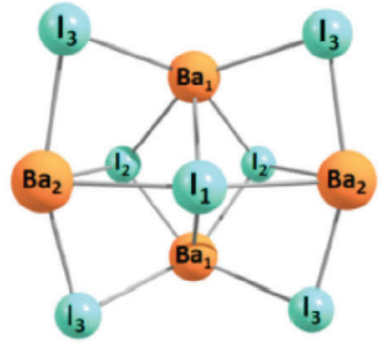

(e)

Fig. 25. Examples of barium halide structures in the gas phase: a) $\left.\mathrm{Ba}_{3} \mathrm{~F}_{5}^{+}, \mathrm{b}\right) \mathrm{Ba}_{4} \mathrm{~F}_{7}^{+}, \mathrm{c}$ ) $\mathrm{BaI}_{2}$, d) $\mathrm{BaI}_{3}^{-}$, e) $\mathrm{Ba}_{2} \mathrm{I}_{3}^{+}$, f) $\mathrm{Ba}_{4} \mathrm{I}_{7}^{+}$(images taken with permission from [109,110]).
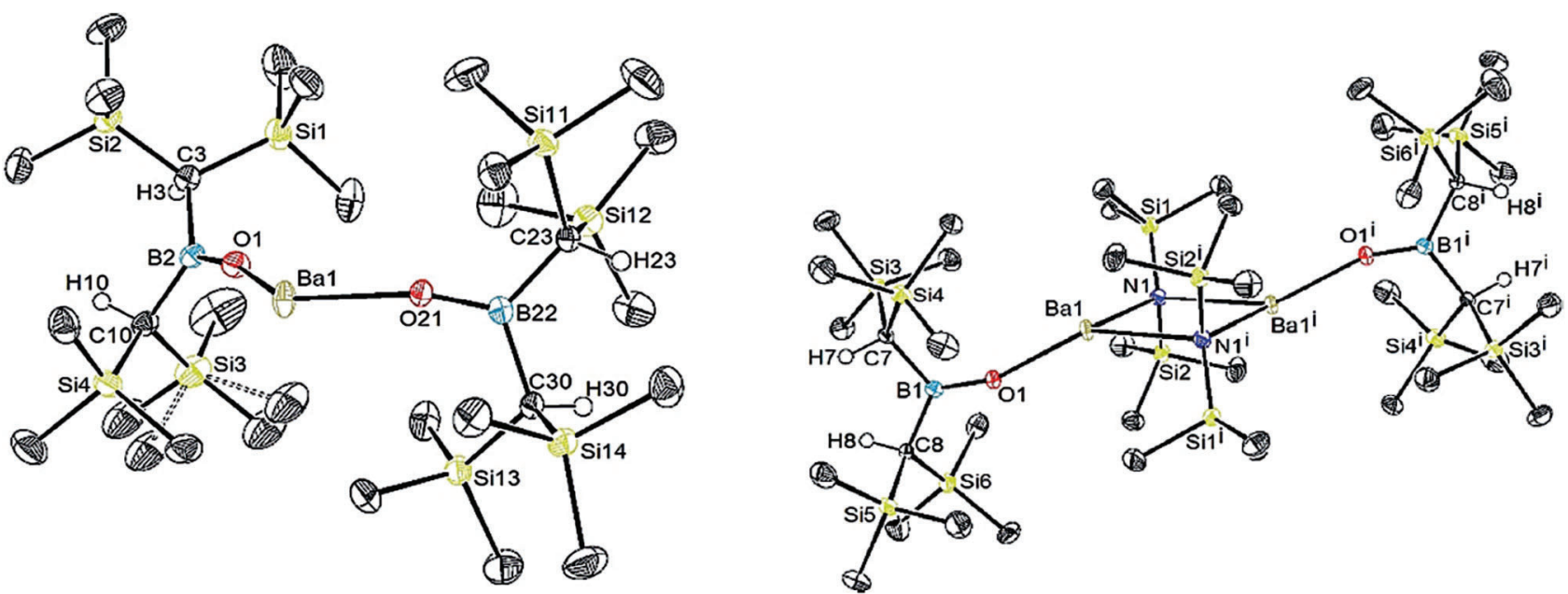

Fig. 26. The bent 2- and distorted trigonal 3-coordinate examples of barium boryloxides (images taken with permission from [111]). 

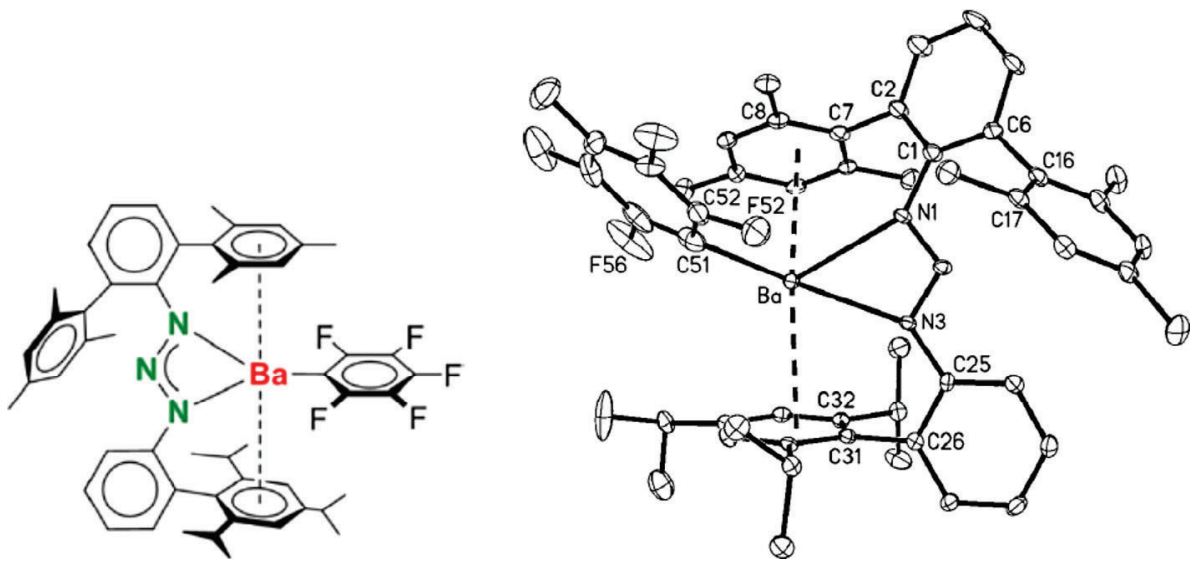

Fig. 27. $\left[\mathrm{Ba}\left(\mathrm{C}_{6} \mathrm{~F}_{5}\right)\left(\mathrm{N}_{3} \mathrm{ArAr}^{\prime}\right)\right]$ (scheme (left) taken with permission from [113]; crystal structure (right) from [80]).
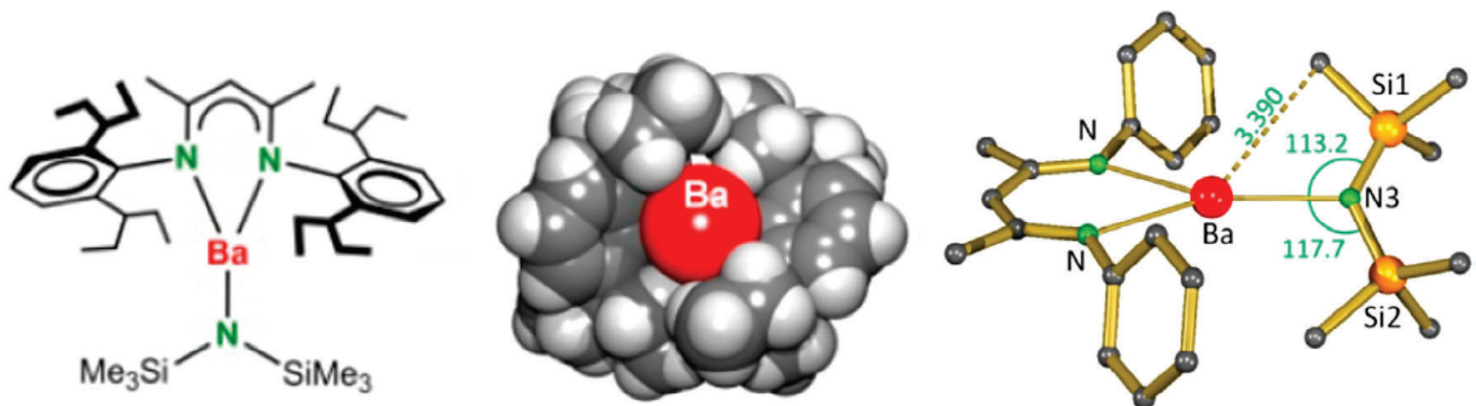

Fig. 28. Heteroleptic barium amide complexes stabilized by a superbulky $\beta$ diketiminate ligand (with permission from [113]).

Coordination number 6 is reached e.g. when metallic barium is reacted with 1,4-diaza-1,3-diene derivatives, as for example in the DME-stabilized $\left(D^{2} D^{\text {Dipp }}\right)_{2} \mathrm{Ba}(\mathrm{DME})$, where $\mathrm{DAD}^{\mathrm{Dipp}}=\mathrm{N}, \mathrm{N}^{\prime}$-bis $($ dii sopropylphenyl)-1,4-diaza-1,3-butadiene (Fig. 29) [114].

Coordination numbers 7 or 8 for barium were achieved by shielding one side of the coordination sphere with a crown ether type ligand that is too small to accommodate the cation, and hence binds in a side-on manner using all five donor atoms [115]. The remaining positions at the barium ion are then taken by bulky $\mathrm{N}$ donor ligands, as shown in Scheme 8. The crystal structures of these compounds indicate additional weak interactions between $\mathrm{H}$-atoms of the silyl and/or adamantyl moieties with the alkaline earth metal ion, and compounds were shown to be catalytically active in the hydrophosphination of vinylarenes.

In mixed metal coordination polymers using iron hexacyanoferrate and trifluoroacetate as bridging ligands, as well as 1,10- phenanthroline as terminal ligands, the two-dimensional coordination polymer $\left.\left\{\left[\mathrm{Ba}_{6} \text { (Phen }\right)_{12}\left(\mathrm{CF}_{3} \mathrm{COO}\right)_{6}\left\{\mathrm{Fe}(\mathrm{CN})_{6}\right\}_{2}\left(\mathrm{H}_{2} \mathrm{O}\right)_{8}\right] \cdot 6 \mathrm{H}_{2} \mathrm{O}\right\}_{\mathrm{n}}$ was obtained, in which the coordination number of the barium ion is 8 [116].

Coordination number 9 is realized for example in Schiff base complexes of barium using the tridentate ligand 2pyridylcarboxaldehyde isonicotinoylhydrazone, L. Two such ligands coordinate to the alkaline earth metal ion in addition to two water ligands and one perchlorate anion to yield $\left\{\left[\mathrm{Ba}(\mathrm{L})_{2}\left(\mathrm{H}_{2^{-}}\right.\right.\right.$ $\left.\left.\mathrm{O})_{2}\left(\mathrm{ClO}_{4}\right)\right]\left(\mathrm{ClO}_{4}\right)\right\}[117]$.

Barium coordination polymers with dinuclear metal ion nodes reminiscent of paddlewheel structures, as the ones known for e.g. $\left[\mathrm{Cu}_{2}(\mathrm{Ac})_{4}\right]$ [118] have been realized with trans-1,2-bis(4pyridyl)ethylene as connecting ligand and thiocyanate as bridging anion between two barium ions (Fig. 30). With water as co-ligand and depending on the ligand to metal ion ratio, different dimen-
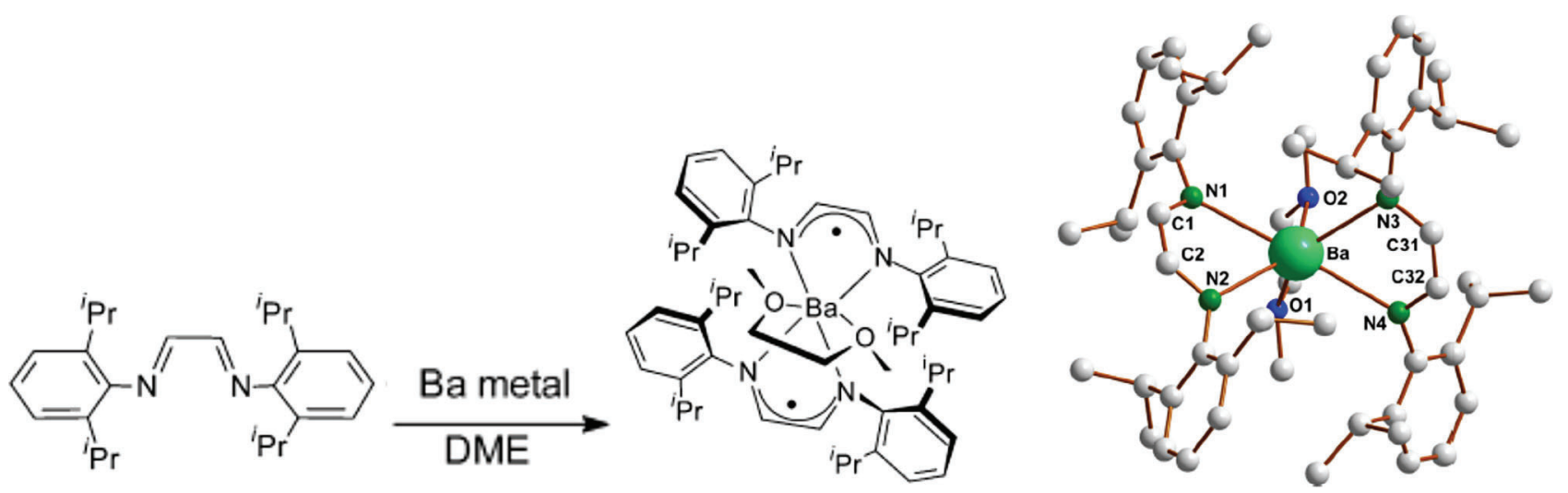

Fig. 29. Direct Synthesis of $D A D^{\text {Dipp }}$ Complex of Ba and its molecular structure (with permission taken from [114]). 

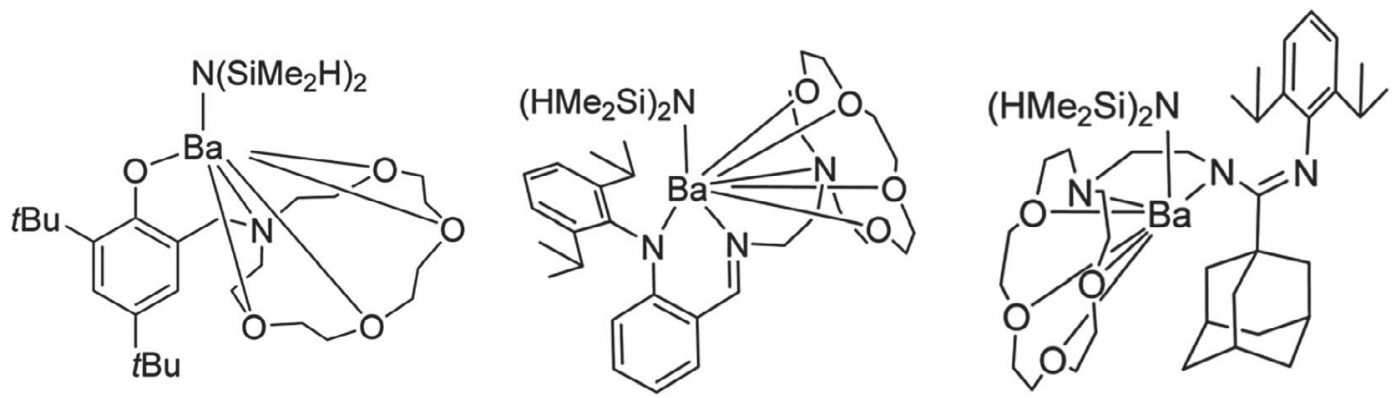

Scheme 8. Crown-ether type ligands for the controlled stabilization of coordination numbers 7 and 8 at the barium ion. (Schemes with permission from [115]).
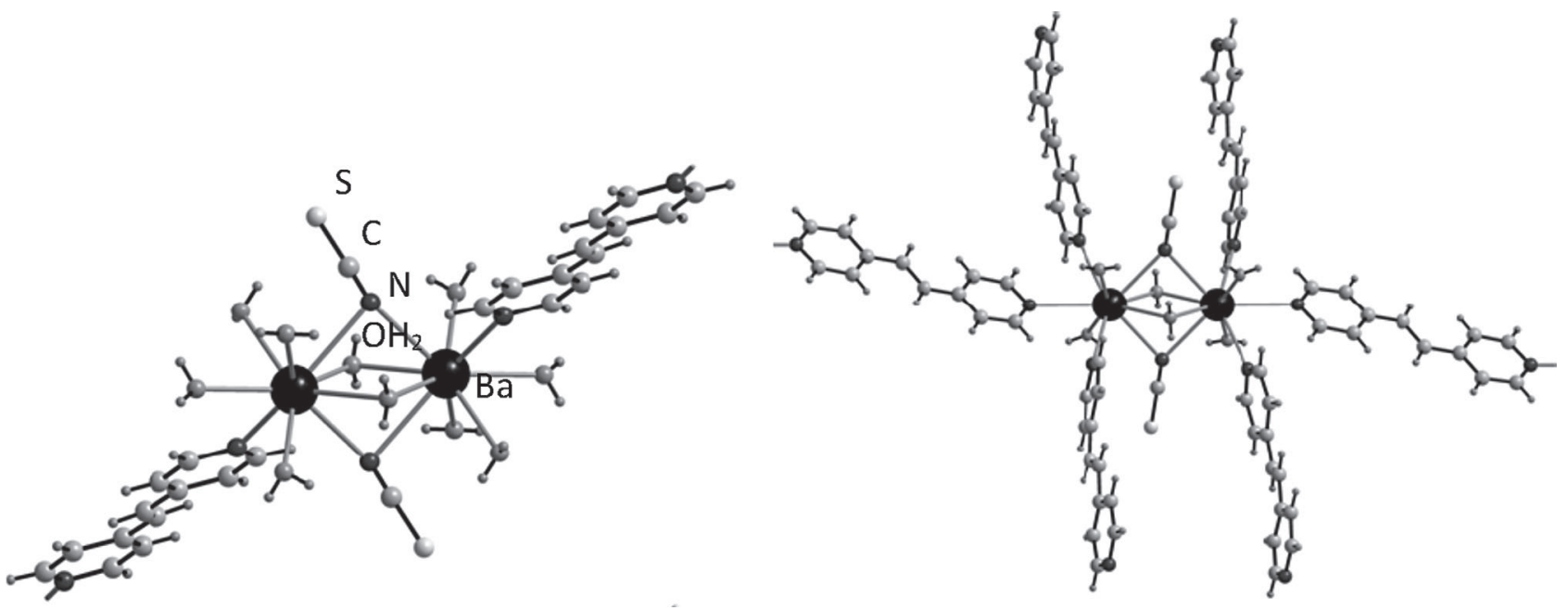

Fig. 30. Barium coordination polymers with coordination number 9 (Images taken with permission from [119]).

sional structures can be obtained [119]. The coordination numbers in such compounds are typically 9 for the barium ions.

Coordination numbers 9 and 10 are realized for example in a one-dimensional coordination polymer with e.g. bridging bipyrimidine derived ligands, in presence of hexafluoroacetylacetonate and methanol as terminal co-ligands. [120]. Two-dimensional structures with the same coordination numbers were obtained when $\mathrm{BaCl}_{2}$ was reacted, depending on the $\mathrm{pH}$, with fully or partially deprotonated $\mathrm{N}, \mathrm{O}$ '-bidentate pyrazine-2,3-dicarboxylate as ligand and water as co-ligand [121]. The coordination geometry is then derived from a monocapped or dicapped tetragonal prism, respectively. The first of these two compounds, $\left\{\left[\mathrm{Ba}\left(\mu-\mathrm{H}_{2} \mathrm{O}\right)\left(\mathrm{H}_{2} \mathrm{O}\right)_{2}(\mu-\right.\right.$ pyzdc $)]\}_{n}$ and $\left\{\left[\mathrm{Ba}\left(\mathrm{H}_{2} \mathrm{O}\right)_{2}(\mu-\mathrm{Hpyzdc})(\mathrm{Hpyzdc})\right] \cdot 2 \mathrm{H}_{2} \mathrm{O}\right\}_{n}$, that have different ligand to metal ion ratios, was used to produce $\mathrm{BaCO}_{3}$ (nano-) particles. Barium-mixed-anion coordination frameworks were obtained from a mixture of barium oxalate, phosphoric acid and diethylamine in water to yield a 9-coordinate barium ion in a two-dimensional structure. The coordination geometry relies on a monocapped tetragonal prism and is completed by water molecules [122]. The coordination chemistry of radium is little explored as it is radioactive, yet seems to be similar to the one of barium [123].

\section{Conclusions}

The coordination chemistry of the alkaline earth metal is a fascinating area of research. It is challenging due to the fact that the closed shell metal ions do not show preferences for specific coordination geometries. Partially covalent (polar) bonds can be the interpretation of the bent structures of the heavier molecular alkaline earth metal halides. Computational studies indicate a contribution of the $d$ orbitals, leading to hybridization of $n s$ and (n-1)d orbitals that can explain the bent geometry. Their behaviour is furthermore far from simple, especially when handled in nonaqueous solvents. Especially in organic solvents, the metal ions and counter ions are not completely separated into ions, but remain intact as solvated molecules. While remaining connected, they can undergo substitution reactions, as for example shown in reaction of the alkaline earth metal iodides in THF solution with alkali alkoxides, leading to elimination of alkali iodide. The evolution of synthetic chemistry has furthermore led to the development of bulky ligands by which the coordination sphere of the alkaline earth metal ion can be better controlled, and through which low coordination numbers can be realized. This allows not only to isolate beautiful new structures of molecular alkaline earth metal compounds, but also of new coordination polymers. If the access to the metal ions can be well controlled, such compounds may serve as catalysts in many useful reactions. Other applications include the (precursor) formation of functional oxide materials, antimicrobial agents or porous materials.

While magnesium and calcium are the best studied among the alkaline earth metal compounds, the heavier alkaline earth metals have not yet been studied in detail, and recent results show the potential progress to be done. The most exciting progress has been made for beryllium, whose chemistry was certainly hampered based on the general knowledge that it is considered as toxic. The newest results show however that this might not be as drastic and has therefore boosted research in beryllium chemistry. Exciting results are also the ones about zero- and monovalent alkaline 
earth metals, whose bonding situation is quite exotic and remains to be fully understood. There is definitely more to come in the near future!

\section{Declaration of Competing Interest}

The authors declare that they have no known competing financial interests or personal relationships that could have appeared to influence the work reported in this paper.

\section{Acknowledgement}

I would like to thank funders such as the Deutsche Forschungsgemeinschaft DFG and the Swiss National Science Foundation SNSF for their generous support of this kind of research.

\section{References}

[1] Book: Alkaline-Earth Metal Compounds: Oddities and Applications, Topics in Organometallic Chemistry, Ed. S. Harder, 2013, Springer-Verlag Berlin, Germany, ISBN 9783642362699; N. S. Poonia, A. V. Bajaj, Coordination chemistry of alkali and alkaline earth cations, Chem. Rev. 79 (1979) 389-445; M. Westerhausen, Synthesis, properties, and reactivity of alkaline earth metal bis[bis\{trialkylsilyl\}amides], Coord. Chem. Rev. 176 (1998) 157-210; K M. Fromm, Oxygen donor stabilized alkaline earth metal iodides, Chimia 57 (2003) 175-178); K. M. Fromm, E. D. Gueneau, Structures of alkali and alkaline earth metal clusters with oxygen donor ligands, Polyhedron 23 (2004) 14791504; K. M. Fromm, E. D. Gueneau, A. Y. Robin, W. Maudez, J. Sague, R. Bergougnant, Recent advances in the chemistry of "clusters" and coordination polymers of alkali, alkaline earth metal and group 11 compounds, Z. Anorg. Allg. Chem. 631 (2005) 1725-1740; M. Westerhausen, Recent developments in the field of organic heterobimetallic compounds of the alkaline-earth metals; Dalton Trans. (2006) 4755-4768; K. M. Fromm, Recent advances in tailoring the aggregation of heavier alkaline earth metal halides, alkoxides and aryloxides from non-aqueous solvents, Dalton Trans. 43 (2006) 51035112; M. Westerhausen, M. Gärtner, R. Fischer, J. Langer, L. Yu, M. Reiher, Heavy Grignard reagents: Challenges and possibilities of aryl alkaline earth metal compounds, Chem. Eur. J. 13 (2007) 6292 - 6306; M. S. Hill, Alkali and alkaline earth metals, Annu. Rep. Prog. Chem., Sect. A 104 (2008) 64-80; G. Arzamendi, E. Arguinarena, I. Campo, S. Zabala, L.M. Gandia, Alkaline and alkaline-earth metals compounds as catalysts for the methanolysis of sunflower oil, Catal. Today 133-135 (2008) 305-313; K. M. Fromm, Coordination polymer networks with s-block metal ions, K. M. Fromm, Coord. Chem. Rev. 252 (2008) 856-885; S. Krieck, L. Yu, M. Reiher, M. Westerhausen, Subvalent organometallic compounds of the alkaline earth metals in low oxidation states, Eur. J. Inorg. Chem. (2010) 197-216; W. D. Buchanan, M. A. Guino-o, K. Ruhlandt-Senge, Highly volatile alkaline earth metal fluoroalkoxides, Inorg. Chem. 49 (2010) 7144-7155; W. D. Buchanan, D. G. Allis, K. Ruhlandt-Senge, Synthesis and stabilization-advances in organoalkaline earth metal chemistry, Chem. Commun. 46 (2010) 44494465; F. Gschwind, A. Crochet. W. Maudez, K. M. Fromm, From alkaline earth ion aggregates via transition metal coordination polymer networks towards heterometallic single source precursors for oxidic materials, Chimia 64 (2010) 299-302; A. Torvisco, K. Ruhlandt-Senge, s-Block Organometallics: Analysis of ion-association and noncovalent interactions on structure and function in benzyl-based compounds, Inorg. Chem. 50 (2011) 12223-12240; A. Torvisco, A. Y. O'Brian, K. Ruhlandt-Senge, Advances in alkaline earth-nitrogen chemistry, Coord. Chem. Rev. 255 (2011) 1268-1292. M. S. Hill, D. J. Liptrot, C. Weetman, Alkaline earths as main group reagents in molecular catalysis, Chem. Soc. Rev. 45 (2016) 972-988; H. Bauer, K. Thum, M. Alonso, C. Fischer, S. Harder, Alkene transfer hydrogenation with alkaline-earth metal catalysts, Angew. Chem. Int. Ed. 58 (2019) 4248-4253; M. S. Gyngazova, L. Grazia, A. Lolli, G. Innocenti, T. Tabanelli, M. Mella, S. Albonetti, F. Cavani, J. Catal. 372 (2019) 61-73.

[2] S.A. Couchman, N. Holzmann, G. Frenking, D.J.D. Wilson, J.L. Dutton, Beryllium chemistry the safe way: a theoretical evaluation of low oxidation state beryllium compounds, Dalton Trans. 42 (2013) 11375-11384.

[3] M. Arrowsmith, H. Braunschweig, M.A. Celik, T. Dellermann, R.D. Dewhurst, W.C. Ewing, T. Kramer, I. Krummenacher, J. Mies, K. Radacki, J.K. Schuster, Neutral zero-valent s-block complexes with strong multiple bonding, Nat. Chem. 8 (2016) 890-894.
[4] G.S. Smith, Q.C. Johnson, D.K. Smith, D.E. Cox, R.L. Snyder, R.-S. Zhou, A. Zalkin, The crystal and molecular structure of beryllium hydride, Solid State Comm. 67 (1988) 491-494.

[5] J.W. Turley, H.W. Rinn, The crystal structure of aluminum hydride, Inorg. Chem. 8 (1969) 18-22.

[6] P.F. Bernath, A. Shayesteh, K. Tereszchuk, R. Colin, The vibration-rotation emission spectrum of free $\mathrm{BeH}_{2}$, Science 297 (2002) 1323-1324.

[7] N.N. Greenwood, A. Earnshaw, Chemistry of the Elements, second ed., Butterworth-Heinemann, 1997, ISBN 0-08-037941-9.

[8] D. Naglav, M.R. Buchner, G. Bendt, F. Kraus, S. Schulz, Off the beaten track - a hitchhiker's guide to beryllium chemistry, Angew. Chem. Int. Ed. 55 (2016) 10562-10576.

[9] E. Wiberg, A.F. Holleman, Inorganic Chemistry, Elsevier, 2001, ISBN 978-0-12352651-9.

[10] L.C. Perera, O. Raymond, W. Henderson, P.J. Brothers, P.G. Plieger, Advances in beryllium coordination chemistry, Coord. Chem. Rev. 352 (2017) 264-290.

[11] M. Müller, M.R. Buchner, Beryllium complexes with bio-relevant functional groups: coordination geometries and binding affinities, Angew. Chem. Int. Ed. 57 (2018) 9180-9184.

[12] I. Despotovic, Complexation of some alkali and alkaline earth metal cations by macrocyclic compounds containing four pyridine subunits - a DFT study, New J. Chem. 39 (2015) 6151-6162.

[13] O. Raymond, L. C. Perera, P. J. Brothers, W. Henderson, P. G. Plieger, The chemistry and metallurgy of beryllium, Chem in New Zealand, July (2015) 137-143.

[14] J.K. Schuster, D.K. Roy, C. Lenczyk, J. Mies, H. Braunschweig, New outcomes of beryllium chemistry: Lewis base adducts for salt elimination reactions, Inorg. Chem. 58 (2019) 2652-2658 (and therein).

[15] V. Nesterov, D. Reiter, P. Bag, P. Frisch, R. Holzner, A. Porzelt, S. Inoue, NHCs in main group chemistry, Chem. Rev. 118 (2018) 9678-9842.

[16] J. Nagamatsu, N. Nakagawa, T. Muranaka, Y. Zenitani, J. Akimitsu, Superconductivity at $39 \mathrm{~K}$ in magnesium diboride, Nature 410 (2001) 63-64.

[17] M.M. Huie, D.C. Bock, E.S. Takeuchi, A.C. Marschilok, K.J. Takeuchi, Cathode materials for magnesium and magnesium-ion based batteries, Coord. Chem. Rev. 287 (2015) 15-27.

[18] T. Mandai, K. Tatesaka, K. Soh, H. Masu, A. Choudhary, Y. Tateyama, R. Ise, H. Imai, T. Takeguchi, K. Kanamura, Modifications in coordination structure of $\mathrm{Mg}[\mathrm{TFSA}]_{2}$-based supporting salts for high-voltage magnesium rechargeable batteries, Phys. Chem. Chem. Phys. 21 (2019) 12100-12111.

[19] Y. Yang, W. Wang, Y. Nuli, J. Yang, J. Wang, High active magnesium trifluoromethanesulfonate-based electrolytes for magnesium-sulfur batteries, ACS Appl. Mater. Interfaces 11 (2019) 9062-9072.

[20] C. Stuhl, R. Anwander, Dimethylmagnesium revisited, Dalton Trans. 47 (2018) $12546-12552$.

[21] Y.O. Wong, L.A. Freeman, A.D. Agakidou, D.A. Dickie, C.E. Webster, R.J. Gilliard, Two carbenes versus one in magnesium chemistry: Synthesis of terminal dihalide, dialkyl, and Grignard reagents; Jr, Organometallics 383 (2019) 688696.

[22] L.A. Freeman, J.E. Walley, A.D. Obi, G. Wang, D.A. Dickie, A. Molino, D.J.D. Wilson, R.J. Gilliard Jr., Stepwise reduction at magnesium and beryllium: Cooperative effects of carbenes with redox non-innocent $\alpha$-diimines, Inorg. Chem. 58 (2019) 10554-10568.

[23] S.P. Green, C. Jones, A. Stasch, Stable magnesium(I) compounds with Mg-Mg bonds, Science 318 (2007) 1754-1757.

[24] K. Yuvaraj, I. Douair, A. Paparo, L. Maron, C. Jones, Reductive trimerization of $\mathrm{CO}$ to the deltate dianion using activated magnesium(I) compounds, J. Am. Chem. Soc. 141 (2019) 8764-8768.

[25] D. Dange, A.R. Gair, D.D.L. Jones, M. Juckel, S. Aldridge, C. Jones, Acyclic 1,2dimagnesioethanes/-ethene derived from magnesium(I) compounds: multipurpose reagents for organometallic synthesis, Chem. Sci. 10 (2019) 3208-3216.

[26] J. Arras, T. Kruczynski, J. Bresien, A. Schulz, H. Schnöckel, Magnesium(I) halide versus magnesium metal: Differences in reaction energy and reactivity monitored in reduction processes of $\mathrm{P}-\mathrm{Cl}$ bonds, Angew. Chem. Int. Ed. 131 (2019) 726-731.

[27] S. Harder, J. Spielmann, J. Intemann, Synthesis and thermal decomposition of a pyridylene-bridged bis- $\beta$-diketiminate magnesium hydride cluster, Dalton Trans. 43 (2014) 14284-14290.

[28] M. Chen, V.E. Jackson, A.R. Felmy, D.A. Dixon, Structures and stabilities of $\left(\mathrm{MgCO}_{3}\right)_{\mathrm{n}}$ clusters, $\mathrm{n} \leq 16$, J. Phys. Chem. A 119 (2015) 3419-3428.

[29] S.G.E.T. Escher, T. Lazauskas, M.A. Zwijnenburg, S.M. Woodley, Synthesis target structures for alkaline earth oxide clusters, Inorganics 6 (29) (2018), https://doi.org/10.3390/inorganics6010029.

[30] A. Hicken, A.J.P. White, M.R. Crimmin, Reversible coordination of boron-, aluminum-, zinc-, magnesium-, and calcium-hydrogen bonds to bent CuL2 fragments: Heavy $\sigma$ complexes of the lightest coinage metal, Inorg. Chem. 56 (2017) 8669-8682.

[31] M. Garçon, C. Bakewell, G.A. Sackman, A.J.P. White, R.I. Cooper, A.J. Edwards, M.R. Crimmin, A hexagonal planar transition-metal complex, Nature (2019), https://doi.org/10.1038/s41586-019-1616-2.

[32] A.O. Atoyebi, C. Brückner, Observations on the mechanochemical insertion of zinc(II), copper(II), magnesium(II), and select other metal(II) ions into porphyrins, Inorg. Chem. 58 (2019) 9631-9642.

[33] Y. Wang, N.A. Maxi, Y. Xie, P. Wei, H.F. Schaefer III, G.H. Robinson, Lewis basecomplexed magnesium dithiolenes, Chem. Commun. 55 (2019) 8087-8089. 
[34] R. Fischer, H. Görls, P.R. Meisinger, R. Suxdorf, M. Westerhausen, Structuresolubility relationship of 1,4-dioxane complexes of di (hydrocarbyl)magnesium, Chem. Eur. J. 25 (2019) 12830-12841.

[35] S. Banerjee, A.P. Ankur, B. Andrews, A. Varghese, Venugopal, Amidomagnesium cations, Dalton Trans. 48 (2019) 7313-7319.

[36] R.M. Slattery, A.E. Stahl, K.R. Brereton, A.L. Rheingold, D.B. Green, J.M. Fritsch, Ring, opening polymerization and copolymerization of L-lactide and $\epsilon$ caprolactone by bis-ligated magnesium complexes, J. Polymer Sci., Part A: Polymer Chem. 57 (2019) 48-59.

[37] Z.-X. Yang, Y. Qian, J.-W. Yu, L. Zhai, W.-W. Zhang, X.-M. Ren, Dimensionality of luminescent coordination polymers of magnesium ions and 1,10ethynebenzene-3,30,5,50-tetracarboxylic acid modulated by structural inducing agents, RSC Adv. 8 (2018) 25489-25499.

[38] J.-S. Hu, S.-J. Dong, K. Wu, X.-L. Zhang, J. Jiang, J. Yuan, M.-D. Zheng, An ultrastable magnesium-organic framework as multi-responsive luminescent sensor for detecting trinitrotoluene and metal ions with high selectivity and sensitivity, Sensors \& Actuators: B. Chemical 283 (2019) 255-261.

[39] X. Shen, Y. Zhang, P. Ma, L. Sutrisno, Z. Luo, Y. Hu, Y. Yu, B. Tao, C. Li, K. Cai, Fabrication of magnesium/zinc-metal organic framework on titanium implants to inhibit bacterial infection and promote bone regeneration, Biomaterials 212 (2019) 1-16.

[40] G. Luo, H. Xie, Y. Niu, J. Liu, Y. Huang, B. Li, G. Li, W. Sun, Electrochemical myoglobin biosensor based on magnesium metal organic frameworks and gold nanoparticles composite modified electrode, Int. J. Electrochem. Sci. 14 (2019) 2405-2413, https://doi.org/10.20964/2019.03.41.

[41] J. Xu, Y. Yu, G. Li, S. Wang, Y. Liu, D. Liu, C. Wang, A porous magnesium metalorganic framework showing selective adsorption and separation of nitrile guest molecules, RSC Adv. 6 (2016) 104451-104455.

[42] N. Xu, Q Zhang B. Hou, Q Cheng, G, Zhang, A novel magnesium metalorganic framework as a multiresponsive luminescent sensor for Fe(III) ions, pesticides, and antibiotics with high selectivity and sensitivity, Inorg. Chem. 57 (2018) 13330-13340.

[43] R. Gil-San-Millan, E. López-Maya, A.E. Platero-Prats, V. Torres-Pérez, P. Delgado, A.W. Augustyniak, M.K. Kim, H.W. Lee, S.G. Ryu, J.A.R. Navarro Magnesium exchanged zirconium metal-organic frameworks with improved detoxification properties of nerve agents, DOI:10.1021/jacs.9b05571, J. Am. Chem. Soc. 141 (2019) 11801-11805.

[44] B.M. Wolf, R. Anwander, Chasing multiple bonding interactions between alkaline-earth metals and main-group fragments, Chem. Eur. J. 25 (2019) 8190-8202.

[45] J. Yano, J. Kern, V.K. Yachandra, H. Nilsson, S. Koroidov, J. Messinger, Light dependent production of dioxygen in photosynthesis, Met Ions Life Sci. 15 (2015) 13-43.

[46] Y. Umena, K. Kawakami, J.-R. Shen, N. Kamiya, Crystal structure of oxygenevolving photosystem II at a resolution of $1.9 \AA$, Nature 473 (2011) 55-60.

[47] C. Chen, Y. Chen, R. Yao, Y. Li, C. Zhang, Artificial $\mathrm{Mn}_{4} \mathrm{Ca}$ clusters with exchangeable solvent molecules mimicking the oxygen-evolving center in photosynthesis, Angew. Chem. Int. Ed. 131 (2019) 3979-3982, and therein.

[48] C. Zhang, C. Chen, H. Dong, J.-R. Shen, H. Dau, J. Zhao, A synthetic $\mathrm{Mn}_{4} \mathrm{Ca}-$ cluster mimicking the oxygen-evolving center of photosynthesis, Science 348 (2015) 690-693.

[49] X. Wu, L. Zhao, J. Jin, S. Pan, W. Li, X. Jin, G. Wang, M. Zhou, G. Frenking, Observation of alkaline earth complexes $\mathrm{M}(\mathrm{CO})_{8}(\mathrm{M}=\mathrm{Ca}$, $\mathrm{Sr}$, or $\mathrm{Ba})$ that mimic transition metals, Science 361 (2018) 912-916.

[50] (a) C.R. Landis, R.P. Hughes, F. Weinhold, Comment on "Observation of alkaline earth complexes $\mathrm{M}(\mathrm{CO}) 8(\mathrm{M}=\mathrm{Ca}$, Sr, or $\mathrm{Ba})$ that mimic transition metals", C. R. Landis et al.,, Science (2019), https://doi.org/10.1126/science. aay 2355 ;

(b) L. Zhao, S. Pan, M. Zhou, G. Frenking, Response to Comment on "Observation of alkaline earth complexes $\mathrm{M}(\mathrm{CO}) 8(\mathrm{M}=\mathrm{Ca}$, Sr, or $\mathrm{Ba})$ that mimic transition metals", L. Zhao, et al., Science (2019), https://doi.org/ 10.1126/science.aay5021.

[51] Q. Wang, S. Pan, S. Lei, J. Jin, G. Deng G. Wang L. Zhao, M. Zhou, G. Frenking Octa-coordinated alkaline earth metal-dinitrogen complexes $\mathrm{M}\left(\mathrm{N}_{2}\right)_{8}(\mathrm{M}=\mathrm{Ca}$, Sr, Ba), Nature Comm. 10 (2019) 3375, https://doi.org/10.1038/s41467-01911323.

[52] L.C. O'Brien, P.F. Bernath, Laser spectroscopy of calcium and strontium monocyclopentadienide, J. Am. Chem. Soc. 108 (1986) 5017-5018.

[53] J.M. Brown, D.J. Milton, T.C. Steimle, Studies of the optical spectra of $\mathrm{CaCl}$ and $\mathrm{SrF}$ at sub-Doppler resolution, Faraday Discuss. Chem. Soc. 71 (1981) 151 163.

[54] S. Krieck, H. Görls, L. Yu, M. Reiher, M. Westerhausen, Stable "inverse" sandwich complex with unprecedented organocalcium(I): Crystal structures of $\left[(\text { thf })_{2} \mathrm{Mg}(\mathrm{Br})-\mathrm{C}_{6} \mathrm{H}_{2}-2,4,6-\mathrm{Ph}_{3}\right]$ and [(thf $)_{3} \mathrm{Ca}\left\{\mu-\mathrm{C}_{6} \mathrm{H}_{3}-1,3,5-\mathrm{Ph}_{3}\right\} \mathrm{Ca}$ (thf $\left.)_{3}\right], \mathrm{J}$ Am. Chem. Soc. 131 (2009) 2977-2985.

[55] I.R. Speight, S.C. Chmely, T.P. Hanusa, A.L. Rheingold, Mechanochemically directed metathesis in group 2 chemistry: calcium amide formation without solvent, Chem. Commun. 55 (2019) 2202-2205.

[56] X. Shi, G. Qin, Y. Wang, L. Zhao, Z. Liu, J. Cheng, Super-bulky pentaarylcyclopentadienyl ligands: Isolation of the full range of half-sandwich heavy alkaline-earth metal hydrides, Angew. Chem. Int. Ed. 58 (2019) 4356 4360.

[57] J. Dyall, M.S. Hill, M.F. Mahon, L. The, A.S.S. Wilson, Calcium formamidinate derivatives by hydride insertion of carbodiimides, Dalton Trans. 48 (2019) 4248-4254.
[58] A.G.M. Barrett, M.R. Crimmin, M.S. Hill, P.A. Procopiou, Heterofunctionalization catalysis with organometallic complexes of calcium, strontium and barium, Proc. R. Soc. A 466 (2010) 927-963.

[59] A. Koch, Q. Dufrois, M. Wirgenings, H. Görls, S. Krieck, M. Etienne, G. Pohnert M. Westerhausen, Direct synthesis of heavy Grignard reagents: Challenges, limitations, and derivatization, Chem. Eur. J. 24 (2018) 16840-16850.

[60] B.M. Wolf, C. Stuhl, C. Maichle-Mössmer, R. Anwander, Dimethylcalcium, J. Am. Chem. Soc. 140 (2018) 2373-2383.

[61] Andrew S. S. Wilson, Michael S. Hill, Mary F. Mahon, Calcium hydride insertion reactions with unsaturated C-C bonds, Organometallics 38 (2019) 351-360.

[62] M. Westerhausen, A. Koch, H. Görls, S. Krieck, Heavy Grignard reagents: Synthesis, physical and structural properties, chemical behavior, and reactivity, Chem. Eur. J. 23 (2017) 1456-1483.

[63] J.F. Kögel, L.H. Finger, N. Frank, J. Sundermeyer, The new $\mathrm{NH}$-acid $\mathrm{HN}\left(\mathrm{C}_{6} \mathrm{~F}_{5}\right)(\mathrm{C}$ $\left.\left(\mathrm{CF}_{3}\right)_{3}\right)$ and its crystalline and volatile alkaline and earth alkaline metal salts, Inorg. Chem. 53 (2014) 3839-3846.

[64] H. Roueindeji, A. Ratsifitahina, T. Roisnel, V. Dorcet, S. Kahlal, J.-Y. Saillard, J. F. Carpentier, Y. Sarazin, Metal...F@C bonding in low-coordinate alkaline earth fluoroarylamides, Chem. Eur. J. 25 (2019) 8854-8864.

[65] M. Kr Barman, A. Baishya, S. Nembenna, Bulky guanidinate calcium and zinc complexes as catalysts for the intramolecular hydroamination, J. Organomet. Chem. 887 (2019) 40-47.

[66] W. Maudez, M. Meuwly, K.M. Fromm, Analogy of the coordination chemistry of alkaline earth metal and lanthanide $\mathrm{Ln}^{2+}$ ions: the isostructural zoo of mixed metal cages $\left[\mathrm{IM}(\mathrm{OtBu})_{4}\{\mathrm{Li}(\mathrm{thf})\}_{4}(\mathrm{OH})\right] \quad(\mathrm{M}=\mathrm{Ca}, \quad \mathrm{Sr}, \mathrm{Ba}, \mathrm{Eu})$ $\left[\mathrm{MM}_{6}(\mathrm{OPh})_{8}(\text { thf })_{6}\right]\left(\mathrm{M}=\mathrm{Ca}, \mathrm{Sr}, \mathrm{Ba}, \mathrm{Sm}, \mathrm{Eu}, \mathrm{M}^{\prime}=\mathrm{Li}, \mathrm{Na}\right)$, and their derivatives with 1,2-dimethoxyethane, Chem. Eur. J. 13 (2007) 8302-8316.

[67] G. Abd-Elmonsef Mahmoud, A.S.A. Zidan, A.A.M. Aly, Hanan K. Mosbah, A.B.M Ibrahim, Calcium and strontium anthranilato complexes as effective Fusarium moniliforme controlling agents, Appl. Organometal Chem. 33 (2019) e4740, https://doi.org/10.1002/aoc.4740.

[68] S. Noro, J. Mizutani, Y. Hijikata, R. Matsuda, H. Sato, S. Kitagawa, K. Sugimoto, Y. Inubushi, K. Kubo, T. Nakamura, Porous coordination polymers with ubiquitous and biocompatible metals and a neutral bridging ligand, Nat. Commun. 6 (2015) 5851, https://doi.org/10.1038/ncomms6851.

[69] D. Banerjee, Z. Zhang, A.M. Plonka, J. Li, J.B. Parise, A calcium coordination framework having permanent porosity and high $\mathrm{CO}_{2} / \mathrm{N}_{2}$ selectivity, Cryst. Growth Des. 12 (2012) 2162-2165.

[70] F. Ke, C. Peng, T. Zhang, M. Zhang, C. Zhou, H. Cai, J. Zhu, X. Wan, Fumaratebased metal-organic frameworks as a new platform for highly selective removal of fluoride from brick tea, Sci. Rep. 8 (2018) 939, https://doi.org/ 10.1038/s41598-018-19277-2.

[71] W. Xu, L.-S. Li, R.-M. Zhong, D.-J. Cai, Q.-O. Zhan, W.-O. Lin, Z.-M. Zhang, J.-Z. $\mathrm{Wu}, \mathrm{Y} .-\mathrm{C} . \mathrm{Ou}$, Synthesis, structures, and one/two-photon excited fluorescence of two new $\mathrm{Ca}$ (II)-coordinated polymers with D- $\pi$-A ligand, J. Coord. Chem. 72 (2019) 1865-1875.

[72] P.S. Kubiak, A.L. Johnson, PJ. Cameron, G. Kociok-Köhn, Single source precursors for calcium sulfide (CaS) deposition, Eur. J. Inorg. Chem. 3962 3969 (2019)

[73] F. Dankert, C. Donsbach, C.-N. Mais, K. Reuter, C. von Hänisch, Alkali and alkaline earth metal derivatives of disila-bridged podands: Coordination chemistry and structural diversity, Inorg. Chem. 57 (2018) 351-359.

[74] B.M. Wolf, C. Stuhl, C. Maichle-Mössmer, R. Anwander, Calcium tetraalkylaluminate and tetramethylgallate complexes supported by the bulky scorpionate ligand $\mathrm{Tp}^{\mathrm{tBu}, \mathrm{Me}}$, Organometallics 38 (2019) 1614-1621.

[75] S.-P. Chia, E. Carter, H.-W. Xi, Y. Li, C.-W. So, Group II metal complexes of the germylidendiide dianion radical and germylidenide anion, Angew. Chem. Int. Ed. 53 (2014) 8455-8458.

[76] F.R. Fortea-Pérez, J. Pasán, A. Pascual-Alvarez, C. Ruiz-Pérez, M. Julve, F. Lloret One-dimensional oxalato-bridged heterobimetallic coordination polymers by using [the $\left[\mathrm{Cr}(\right.$ pyim $\left.)\left(\mathrm{C}_{2} \mathrm{O}_{4}\right)_{2}\right]-$ complex as metalloligand [pyim=2- $\left(2^{\prime}-\right.$ pyridyl)imidazole], Inorg. Chim. Acta 486 (2019) 150-157.

[77] A. Finelli, N. Hérault, A. Crochet, K.M. Fromm, Compartmentalization of alkaline earth metals in salen-type $\mathrm{Cu}$ - and Ni-complexes in solution and in the solid state, ACS Omega 4 (2019) 10231-10242.

[78] S.D. Robertson, M. Uzelac, R.E. Mulvey, Alkali-metal-mediated synergistic effects in polar main group organometallic chemistry, Chem. Rev. 119 (2019) $8332-8405$

[79] Regina G. Szlag, B. Leopoldo Suescun, Dulani Dhanapala, Federico A Rabuffetti, Rubidium-alkaline-earth trifluoroacetate hybrids as selffluorinating single-source precursors to mixed-metal fluorides, Inorg. Chem. 58 (2019) 3041-3049.

[80] Sven-Oliver Hauber, Falk Lissner, Glen B. Deacon, Mark Niemeyer, Stabilization of aryl-calcium, -strontium, and -barium compounds by designed steric and $\pi$-bonding encapsulation, Angew. Chem. Int. Ed. 44 (2005) 5871-5875.

[81] S. Datta, M.T. Gamer, P.W. Roesky, Aminotroponiminate calcium and strontium complexes, Dalton Trans. 2839-2843 (2008).

[82] A.J. Bridgeman, The shapes of bis(cyclopentadienyl) complexes of the s-block metals, J. Chem. Soc., Dalton Trans. (1997), 2887-2893 and therein.

[83] M.D. Walter, G. Wolmershäuser, H. Sitzmann, Calcium, strontium, barium, and ytterbium complexes with cyclooctatetraenyl or cyclononatetraenyl ligands, J. Am. Chem. Soc. 127 (2005) 17494-17503, and therein.

[84] F.M. Sroor, L. Vendier, M. Etienne, Cyclooctatetraenyl calcium and strontium amido complexes, Dalton Trans. 47 (2018) 12587-12595. 
[85] S. Mondal, J.L. Cabellos, S. Pan, E. Osorio, J.J. Torres-Vega, W. Tiznado, A Restrepo, G. Merino, 10- $\pi$-Electron arenes à la carte: structure and bonding of the $\left[\mathrm{E}-\left(\mathrm{C}_{\mathrm{n}} \mathrm{H}_{\mathrm{n}}\right)-\mathrm{E}\right]^{\mathrm{n}-6}(\mathrm{E}=\mathrm{Ca}, \mathrm{Sr}, \mathrm{Ba} ; \mathrm{n}=6-8)$ complexes, Phys. Chem. Chem. Phys. 18 (2016) 11909-11918.

[86] A.G.M. Barrett, M.R. Crimmin, M.S. Hill, P.A. Procopiou, Heterofunctionalization catalysis with organometallic complexes of calcium, strontium and barium, Proc. R. Soc. A 455 (2010) 927-963.

[87] B. Rösch, T.X. Gentner, H. Elsen, C.A. Fischer, J. Langer, M. Wiesinger, S. Harder, Nucleophilic aromatic substitution at benzene with powerful strontium hydride and alkyl complexes, Angew. Chem. Int. Ed. 58 (2019) 5396-5401.

[88] S.P. Sarish, H.W. Roesky, M. John, A. Ringe, J. Magull, Well-defined hydrocarbon soluble strontium fluoride and chloride complexes of composition $\left[\mathrm{LSr}(\right.$ thf $\left.)(\mu-\mathrm{F})_{2} \mathrm{Sr}(\text { thf })_{2} \mathrm{~L}\right]$ and $\left[\mathrm{LSr}(\operatorname{thf})(\mu-\mathrm{Cl})_{2} \mathrm{Sr}(\text { thf })_{2} \mathrm{~L}\right]$, Chem. Commun. 2390-2392 (2009).

[89] S.M. George, H.-S. Kim, M.S. Lah, B.K. Park, C.G. Kim, T.-M. Chung, Synthesis of new heteroleptic strontium complexes, Dalton Trans. 43 (2014) 1446114469.

[90] B. Maitland, M. Wiesinger, J. Langer, G. Ballmann, J. Pahl, H. Elsen, C. Färber, S. Harder, A simple route to calcium and strontium hydride clusters, Angew. Chem. Int. Ed.56 (2017) 11880-11884.

[91] K.M. Fromm, E.D. Gueneau, A.Y. Robin, W. Maudez, J. Sague, R. Bergougnant, Recent advances in the chemistry of "clusters" and coordination polymers of alkali, alkaline earth metal and group 11 compounds, Z. Anorg. Allg. Chem. 631 (2005) 1725-1740.

[92] D.K. Sinitsa, T.S. Sukhikh, P.A. Petrov, V.A. Nadolinny, S.N. Konchenko, N.A. Pushkarevsky, Structural diversity of calcium, strontium, and barium complexes with reduced forms of the 3,6-di-tert-butyl-obenzoquinone ligand, Eur. J. Inorg. Chem. 4373-4383 (2019).

[93] A. Balendra, V. Banday, S. Kumar, A. Murugavel, Ramanan, Strontiumcarboxylate-based coordination polymers: synthesis, structure and dielectric properties, Chem. Select 4 (2019) 4756-4766.

[94] M. Sanchez, M.J. Harvey, F. Nordstrom, S. Parkin, D.A. Atwood, Salen-type compounds of calcium and strontium, Inorg. Chem. 41 (2002) 5397-5402.

[95] P.W. Roesky, Syntheses and structures of strontium, barium, and europium bis(diphosphanylamido) complexes, Inorg. Chem. 45 (2006) 798-802.

[96] Z. Fei, T.J. Geldbach, D. Zhao, R. Scopelliti, P.J. Dyson, A nearly planar water sheet sandwiched between strontium-imidazolium carboxylate coordination polymers, Inorg. Chem. 44 (2005) 5200-5202.

[97] A.-A. Al-Terkawi, G. Scholz, F. Emmerling E. Kemnitz, Strontium-coordination polymers based on tetrafluorophthalic and phthalic acids: mechanochemical synthesis, ab initio structures determination, and spectroscopic characterization, Dalton Trans. 46 (2017) 12574-12587.

[98] I. Loa, R.J. Nelmes, L.F. Lundegaard, M.I. McMahon, Extraordinarily complex crystal structure with mesoscopic patterning in barium at high pressure, Nature Materials 11 (2012) 627-632.

[99] K.M. Fromm, Ionic or covalent? Can some first hints be derived from the solid state structures of alkaline earth metal halide adducts?, CrystEngComm 4 (2002) 318-322.

100] M. Hargittai, Molecular structure of metal halides, Chem. Rev. 100 (2000) 2233-2301, and therein.

01] M. Vasiliu, J.G. Hill, K.A. Peterson, D.A. Dixon, Structures and heats of formation of simple alkaline earth metal compounds II: Fluorides, chlorides, oxides and hydroxides for Ba, Sr and Ra, J. Phys. Chem. A. 122 (2018) 316327.

102] M. Vasiliu, D. Feller, J.L. Gole, D.A. Dixon, Structures and heats of formation of simple alkaline earth metal compounds: Fluorides, chlorides, oxides and hydroxides for Be, Mg, and Ca, J. Phys. Chem. A. 114 (2010) 9349-9358.

103] M.A. Guino-o, A. Torvisco, W. Teng, K. Ruhlandt-Senge, Alkaline earth metal di- and triphenylmethanides: Analysis of ion association modes, Inorg. Chim. Acta 389 (2012) 122-130.

[104] M.A. Guino-o, J.S. Alexander, M.L. McKee, H. Hope, U.B. Englich, K. RuhlandtSenge, When VSEPR fails: Experimental and theoretical investigations of the behavior of the alkaline-earth-metal acetylides, Chem. Eur. J. 15 (2009) $11842-11852$

[105] H. Hagemann, V. D’Anna, M. Lawson Daku, F. Kubel, Crystal chemistry in the barium fluoride chloride system, Cryst. Growth Des. 12 (2012) 1124-1131.
[106] K.M. Fromm, Structural evolution from the solid state to the molecule for $\mathrm{BaI}_{2}$ : synthesis and crystal structures of $\left[\mathrm{BaI}_{2}\left(\mu_{2}-\mathrm{OH}_{2}\right)_{2}\right]_{3 / \infty},\left[\mathrm{BaI}_{2}\left(\mu_{2}-\mathrm{OH}_{2}\right)\right.$ $\left.\left(\mathrm{OC}_{3} \mathrm{H}_{6}\right)\right]_{2 / \infty},\left[\mathrm{BaI}_{2}(\text { thf })_{3}\right]_{1 / \infty}$, and $\left[\mathrm{BaI}_{2}(\text { thf })_{5}\right] \cdot$ THF, Angew. Chem. 109 (1997) 2876-2878, Angew. Chem. Int. Ed. Engl. 36 (1997) 2799-2801.

[107] D. Stinghen, A.L. Rüdiger, S.O.K. Giese, G.G. Nunes, J.F. Soares, D.L. Hughes, Cobalt(II) chloride adducts with acetonitrile, propan-2-ol and tetrahydrofuran: considerations on nuclearity, reactivity and synthetic applications, Acta Cryst C 37 (2017) 104-114.

[108] L.S. Fitts, E.J. Bierschenk, T.P. Hanusa, A.L. Rheingold, M. Pink, V.G. Young Jr, Selective modification of the metal coordination environment in heavy alkaline-earth iodide complexes, New J. Chem. 40 (2016) 8229-8238.

[109] F. Jacob, A.M. Pogrebnoi, T.P. Pogrebnaya, Cluster ions in saturated vapor over barium difluoride: Structure and thermodynamic properties, Comput. Theor. Chem. 1091 (2016) 137-149.

[110] F. Jacob, T.P. Pogrebnaya, A.M. Pogrebnoi, Ionic species in vapour over barium diiodide: Quantum chemical study of structure and thermodynamic properties, Comput. Theor. Chem. 1117 (2017) 196-206.

[111] E. Le Coz, V. Dorcet, T. Roisnel, S. Tobisch, J.-F. Carpentier, Y. Sarazin, Lowcoordinate barium boryloxides: Synthesis and dehydrocoupling catalysis for the production of borasiloxanes, Angew. Chem. Int. Ed. 57 (2018) 1174711751.

[112] Y. Takahashi, A. O’Brien, G.B. Deacon, P.C. Andrews, M. Wolf, A. Torvisco, M.M. Gillett-Kunnath, K. Ruhlandt-Senge, A modern twist to a classic synthetic route: $\mathrm{Ph}_{3} \mathrm{Bi}$-based redox transmetalation protolysis (RTP) for the preparation of barium metalorganic species, Inorg. Chem. 56 (2017) $11480-11489$

[113] T.X. Gentner, B. Rösch, K. Thum, J. Langer, G. Ballmann, J. Pahl, W.A. Donaubauer, F. Hampel, S. Harder, Heteroleptic heavier alkaline earth metal amide complexes stabilized by a superbulky $\beta$-diketiminate ligand, Organometallics 38 (2019) 2485-2493.

[114] V. Lorenz, C.G. Hrib, D. Grote, L. Hilfert, M. Krasnopolski, F.T. Edelmann, Diazadiene complexes of the heavy alkaline-earth metals strontium and barium: Structures and reactivity, Organometallics 32 (2013) 4636-4642.

[115] E. Le Coz, H. Roueindeji, T. Roisnel, V. Dorcet, J.-F. Carpentier, Y. Sarazin, Barium complexes with crown-ether-functionalised amidinate and iminoanilide ligands for the hydrophosphination of vinylarenes, Dalton Trans. 48 (2019) 9173-9180.

[116] N.K. Karan, B. Samanta, S. Mitra, V. Gramlich, A new polymeric barium-iron (III) complex with chain and large ring structure, Z. Naturforsch. 60b (2005) 640-644.

[117] B. Parmar, K.K. Bisht, P. Maiti, P. Paul, E. Suresh, Syntheses, characterization and crystal structures of potassium and barium complexes of a Schiff base ligand with different anions, J. Chem. Sci. 126 (2014) 1373-1384.

[118] see for example M. Mikuriya, R. Indrawati, R. Hashido, S. Matsubara, C. Nakamura, D. Yoshioka, K. Yokota, M. Fukuzaki, M. Handa, Chain compounds based on paddle-wheel copper(II) carboxylate bearing four nitroxide radicals Magnetochemistry 4 (2018) 22, https://doi.org/ 10.3390/magnetochemistry4020022.

[119] S. Wöhlert, I. Jess, C. Näther, Synthesis Crystal structures and properties of new barium thiocyanato coordination polymers with trans-1,2-bis(4-pyridyl) ethylene as ligand, Z, Naturforsch. 66b (2011) 133-141.

[120] F. Pointillart, K. Boubekeur, P. Herson, C. Train, Barium one-dimensional coordination polymers from barium $\beta$-diketonates and 2,2'-bipyrimidine derivatives, CrystEngComm 12 (2010) 3430-3436.

[121] M. Tabatabaee, B.-M. Kukovec, S. Amjad, M.R. Shishebor, Two different barium(II) 2D coordination polymers constructed with pyrazine-2,3dicarboxylate: Synthesis, crystal structures, and thermal decomposition to barium(II) carbonate nanoparticles, Aust. J. Chem. 69 (2016) 1261-1267.

[122] S.J. Iveson, C.B. Johnston, W.T.A. Harrison, Barium oxalates combined with oxo-anions and organic cations: Syntheses and structures of $\mathrm{Ba}_{2}\left(\mathrm{C}_{2} \mathrm{O}_{4}\right)$ $\left(\mathrm{H}_{2} \mathrm{PO}_{3}\right)_{2}$ and $\mathrm{C}_{2} \mathrm{H}_{10} \mathrm{~N}_{2} \cdot \mathrm{Ba}\left(\mathrm{H}_{2} \mathrm{O}\right)_{2}\left(\mathrm{HC}_{2} \mathrm{O}_{4}\right)_{4}$, Crystals 1 (2011) 59-68.

[123] A. Matyskin V., N. Hansson L., P. Brown L., C. Ekberg, Barium and radium complexation with ethylenediaminetetraacetic acid in aqueous alkaline sodium chloride media, J. Solution Chem. (2017), https://doi.org/10.1007/ s10953-017-0679-7. 